\title{
The Spatial Structure of Tidal and Mean Circulation over the Inner Shelf South of Martha's Vineyard, Massachusetts
}

\author{
Anthony R. KiRincich, SteVen J. Lentz, And J. Thomas FARRAR \\ Woods Hole Oceanographic Institution, Woods Hole, Massachusetts \\ NEIL K. GANJU \\ U.S. Geological Survey, Woods Hole Coastal and Marine Science Center, Woods Hole, Massachusetts
}

(Manuscript received 14 January 2013, in final form 26 March 2013)

\begin{abstract}
The spatial structure of the tidal and background circulation over the inner shelf south of Martha's Vineyard, Massachusetts, was investigated using observations from a high-resolution, high-frequency coastal radar system, paired with satellite SSTs and in situ ADCP velocities. Maximum tidal velocities for the dominant semidiurnal constituent increased from 5 to $35 \mathrm{~cm} \mathrm{~s}^{-1}$ over the 20 -km-wide domain with phase variations up to $60^{\circ}$. A northeastward jet along the eastern edge and a recirculation region inshore dominated the annually averaged surface currents, along with a separate along-shelf jet offshore. Owing in part to this variable circulation, the spatial structure of seasonal SST anomalies had implications for the local heat balance. Cooling owing to the advective heat flux divergence was large enough to offset more than half of the seasonal heat gain owing to surface heat flux. Tidal stresses were the largest terms in the mean along- and across-shelf momentum equations in the area of the recirculation, with residual wind stress and the Coriolis term dominating to the west and south, respectively. The recirculation was strongest in summer, with mean winds and tidal stresses accounting for much of the differences between summer and winter mean circulation. Despite the complex bathymetry and short along-shelf spatial scales, a simple model of tidal rectification was able to recreate the features of the northeastward jet and match an estimate of the across-shelf structure of sea surface height inferred from the residual of the momentum analysis.
\end{abstract}

\section{Introduction}

The inner shelf south of Martha's Vineyard, Massachusetts (Fig. 1), has been the site of recent work on the dynamics of depth-dependent across-shelf (XS) circulation owing to wind and wave forcing. Using a multiyear dataset of moored velocity and hydrographic observations from the area, Fewings et al. (2008) and Lentz et al. (2008) found significant across-shelf circulation owing to across-shelf winds as well as evidence of a wave-driven circulation in the inner shelf. These and previous innershelf studies generally assumed along-shelf (AS) uniform conditions and removed the time-mean velocity profile from their investigation of the wind-driven dynamics. However, a recent analysis of high-resolution model

Corresponding author address: Anthony Kirincich, Woods Hole Oceanographic Institution, 266 Woods Hole Road, Woods Hole, MA 02543.

E-mail: akirincich@whoi.edu output for the region (Ganju et al. 2011) found significant spatial variability of the depth-independent mean circulation that was not resolved by the moored observations of Fewings et al. (2008) and Lentz et al. (2008). As spatial variability of both the mean and timedependent circulation have the potential to drive significant lateral exchange across the inner shelf, additional observations are needed to fully interpret the drivers, spatial scales, and relative importance of the various mechanisms for lateral exchange on the total exchange present over the inner shelf.

The observed seasonal mean circulation found in the moored observations of Lentz et al. (2008) and Fewings et al. (2008) was generally ascribed to the effects of pressure gradients (Lentz 2008; Fewings and Lentz 2010) or surface gravity waves (Lentz et al. 2008). However, modeling studies of the region by $\mathrm{He}$ and Wilkin (2006) and Wilkin (2006) found that large tidal velocities in the gap between the islands of Martha's Vineyard and Nantucket (Fig. 1) played a critical role in 

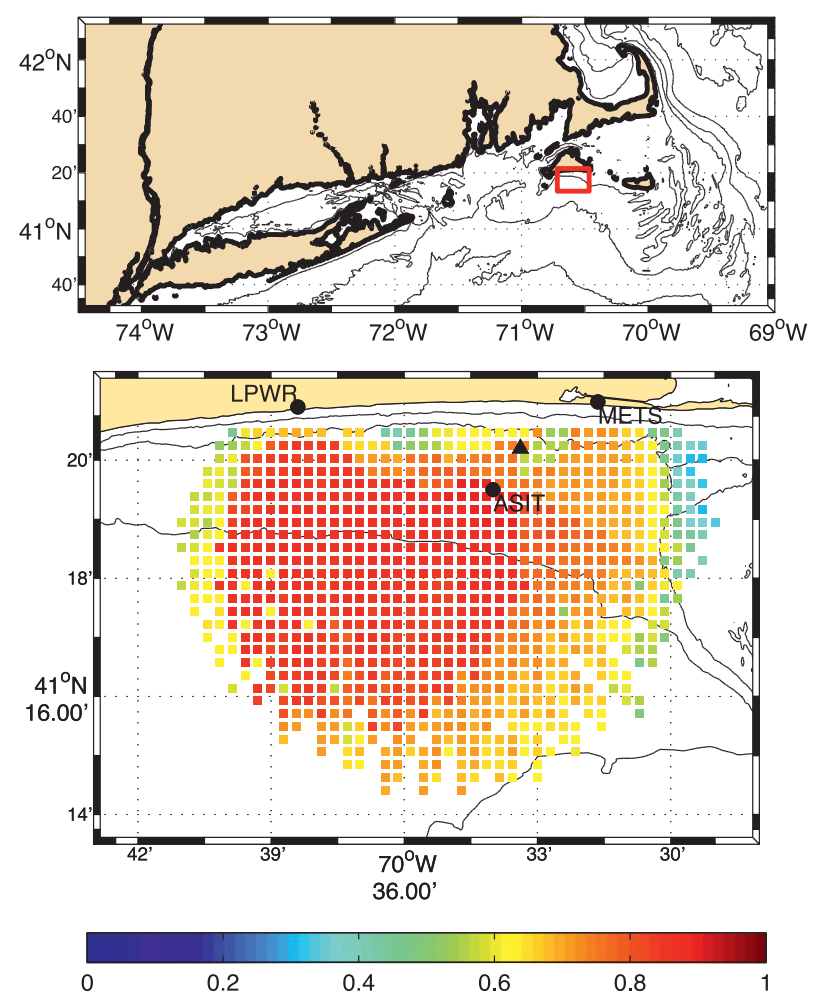

FIG. 1. (top) The southern New England coast with the location south of Martha's Vineyard, Massachusetts (red box), showing (bottom) the inner shelf and installations of the MVCO HF radar system (black circles), the MVCO node (black triangle), along with the cumulative coverage map for the system during 2011.

both tidal and subtidal circulation. In these model simulations, the mean effect of tidal flows had a complex spatial structure, driving a mean exchange of water masses between Vineyard Sound to the north and the New England shelf to the south as well as a mean circulation south and west of the gap.

The model/data comparisons of Ganju et al. (2011) also found a spatially variable circulation that was highly dependent on model resolution. Only the highestresolution model (40-m grid inshore) gave good agreement inshore of the 17-m isobath. Runs utilizing coarser grids, including the same model setup employed by $\mathrm{He}$ and Wilkin (2006) and Wilkin (2006), were unable to match the observed mean currents, in large part due to the effects of unresolved bathymetric features in the coarser-resolution model runs. The high-resolution model results were limited in spatial extent but suggested the presence of a 3-5-km recirculation feature in areas not occupied by the moored observations.

A number of recent studies have documented instances where variations in alongshore currents caused significant depth-independent across-shelf exchange. Bathymetric variability has been shown to lead to the formation of upwelling centers, despite uniform winds (Song et al. 2001; Tilburg and Garvine 2003; Yankovsky and Chapman 1995). Capes, headlands, or seamounts have been shown to eject water masses and materials from the shelf, either due to the offshore flow of the along-shelf current (Barth et al. 2005; Castelao and Barth 2006) or tidal rectified flow (Geyer 1993). Temporally and spatially variable wind and buoyancy forcings have also been tied to spatially variable circulation (Chant et al. 2004; Kirincich and Barth 2009; Yankovsky and Garvine 1998; Kohut et al. 2004).

Given the sensitivity of model results from the region on model resolution, as well as the large spatial variations suggested by the model output, the full range of the spatial variability present in the inner shelf south of Martha's Vineyard and the relative importance of the various mechanisms for across-shelf exchange is not known. What is the full extent of the recirculation region? How does the lateral exchange in areas with strong rectified tidal flow compare with those where only wind or buoyancy forcing are important? How does the background circulation owing to tidal and hydrographic conditions affect or combine with the winddriven circulation present during individual wind events? In part to address these questions, a unique system of high-frequency (HF) radars was designed and deployed by the Woods Hole Oceanographic Institution (WHOI) along the coastal ocean south of Martha's Vineyard. These sensors, which typically measure surface currents up to $150-\mathrm{km}$ offshore with resolutions of $6-8 \mathrm{~km}$ (Kohut et al. 2006; Kosro 2005; Paduan and Graber 1997), were instead configured to resolve circulation variability at high spatial resolutions (approaching $400 \mathrm{~m}$ ) with high accuracy starting just offshore of the surf zone and extending 20-km offshore. The system, described in detail by Kirincich et al. (2012), has been collecting data since the fall of 2010.

The present work seeks to document the spatial structure of the mean surface circulation over the inner shelf south of Martha's Vineyard, investigate the processes that control the observed variability, and explore the implications for exchange across the inner shelf. This represents a first step toward giving spatial context to studies of the wind-driven dynamics in this region and assessing the relative importance of these background processes to the event-scale dynamics on across-shelf exchange. Used along with in situ observations of velocity profiles, hydrography, and wind forcing at the Martha's Vineyard Coastal Observatory (MVCO) and satellite-based sea surface temperature (SST), HF radar surface currents from 2011 provide a comprehensive picture of the surface circulation over the inner shelf. In the text that follows, details about the observational 


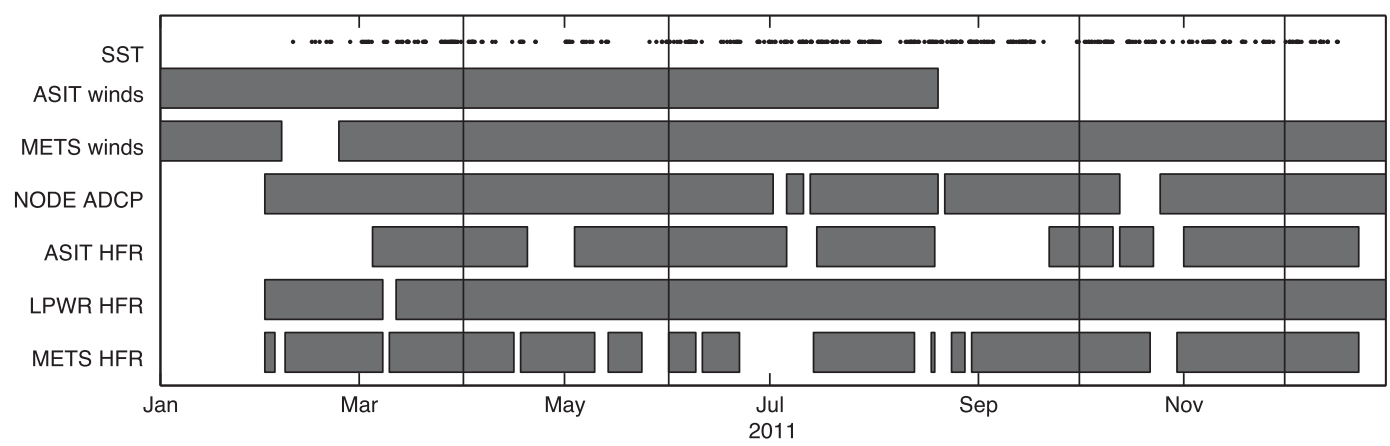

FIG. 2. Data availability during 2011 for the HF radar sites at ASIT, LPWR, and METS, ancillary meteorological and velocity data from MVCO, and times of AVHRR SST imagery with greater than $70 \%$ cloud-free coverage within the footprint of radar-based surface currents.

datasets used are presented first, followed by a description of the spatial structure of the observed tidal velocities in the study area. The mean and seasonal circulation and SST anomalies are presented next, along with estimates of the mean advective heat flux (AHF) divergence. A method to utilize the surface velocities to examine the tidally averaged momentum balances is then presented and used to investigate the dominant processes and their spatial dependence. Finally, the implications of surface advection on the exchange of heat across the inner shelf are discussed in the context of previous studies on depth-dependent heat flux divergence, as are the similarity of the results to a simple analytical model for tidal rectification.

\section{Observations}

\section{a. Surface currents}

The high-frequency radar (HF radar) system at MVCO was designed to map inner-shelf currents at horizontal scales approaching $400 \mathrm{~m}$ (Fig. 1). The system is composed of three closely spaced sites with Seasondetype direction-finding instruments running at operating frequencies near $25 \mathrm{MHz}$ and configured to maximize the spatial and temporal independence of observations over the inner shelf. Two of the three sites are located on land, with one placed at the MVCO Shore Meteorological Station (METS) and the second approximately $10 \mathrm{~km}$ to the west at the Long Point Wildlife Refuge (LPWR). The third site is located on the MVCO AirSea Interaction Tower (ASIT), approximately 4-km offshore south of the island. Additional details about the system and the advanced data processing techniques utilized are given in Kirincich et al. (2012).

During 2011, surface current estimates were available every half hour for an 11-month period starting 5 February and ending 23 December. Data immediately before and after that period were not available due to power outages or equipment failures at the remote sites. Additionally, a number of short-term data losses at the ASIT or METS sites occurred throughout the year (Fig. 2); however, viable data existed in a large fraction of the domain even when only two of the three sites were contributing radial data (Fig. 1). Specific to the data collected during summer 2011, unresolved issues with the radial velocity data from LPWR in the northeast corner of the domain led to the exclusion of LPWR data from bearing angles less than $120^{\circ}$ True $(\mathrm{T})$ for the time period between 1 May and 31 September. This loss of data resulted in reduced coverage northeast of a line between LPWR and ASIT (Fig. 1).

Surface currents from the MVCO system were compared to in situ ADCP and drifter observations to estimate the overall accuracies of the system. The rms differences between near-surface ADCP velocities from the MVCO node, described below, and the radarderived surface currents were 4.7 and $5.2 \mathrm{~cm} \mathrm{~s}^{-1}$ for one half hour time series of the east and north components, respectively. However, rms differences for tidal fits to the datasets were much smaller at $<1 \mathrm{~cm} \mathrm{~s}^{-1}$. Mean spreading rates between observed trajectories from a mass $(\sim 80)$ drifter release performed in the study area on 3-5 August 2011 (Rypina et al. 2013, manuscript submitted to J. Atmos. Oceanic Technol.) and pseudotrajectories estimated from the surface currents were similar to the raw ADCP comparisons for the first hour but then quickly decreased to $2.2 \mathrm{~cm} \mathrm{~s}^{-1}$ for time periods longer than one hour. The advanced techniques described in Kirincich et al. (2012), which examine the characteristics of the received signal and the output of the direction-finding algorithm, to provide independent data quality indicators as well as more representative velocity estimates, were shown to decrease rms differences by up to $2 \mathrm{~cm} \mathrm{~s}^{-1}$ and eliminate observed biases of tidal ellipses estimated using standard methods. 


\section{b. In situ current, meteorological, and hydrographic observations}

This analysis utilizes concurrent velocity, meteorological, and hydrographic observations obtained from the MVCO along with historic velocity observations from a three-year-long mooring array described by Horwitz (2012) - the Stratification, Wind, and Waves on the inner shelf of Martha's Vineyard (SWWIM) arrayto both ground truth the radar-based surface currents and provide information about the forcing conditions present. Data from the MVCO underwater node, located approximately $1.6-\mathrm{km}$ offshore in $12 \mathrm{~m}$ of water, were obtained from their website (http://mvcodata.whoi.edu/ cgi-bin/mvco/mvco.cgi). Velocity profiles from the node during the study period (Fig. 2), composed of 0.5 -m-depth bins from 3.11-m above the bottom to approximately $1-\mathrm{m}$ below the surface, were quality controlled, masked with a tide-following surface mask, and interpolated onto a surface-following coordinate system and half-hour time steps. Estimates of bulk wave statistics, including significant wave height, dominant wave period, and incoming wave direction, were calculated from wave spectra derived from the raw ADCP observations following standard methods. An ADCP-based estimate of the "surface velocity" at the effective depth of the radar, $\sim 25 \mathrm{~cm}$ (Stewart and Joy 1974), was found by linearly extrapolating the top-most three depth bins to the surface. An estimate of the wave-driven Stokes velocity at the effective measurement depth of the radar was formed from the bulk wave statistics and added to the near-surface ADCP observations to better match the radar-obtained surface currents (Ullman et al. 2006; Kirincich et al. 2012). Estimates of tidal velocities and individual constituent magnitudes for both the ADCP and HF radar datasets were calculated using T_tide (Pawlowicz et al. 2002).

Measurements of near-surface wind velocities were made at the METS and ASIT locations. While wind from the two locations was highly correlated during the study period, the wind record at ASIT was believed to be most representative of the winds present over the study area. Thus a composite wind record was created from the ASIT winds, when available, and a modified version of the METS winds when ASIT winds were not available. The MET winds were modified using separate regression coefficients for the onshore and offshore directions to best match ASIT winds during periods of overlapping coverage. Wind stress was estimated from the composite record following the bulk formula of Large and Pond (1981). For the momentum balance calculations in sections 6 and 7 , the wind stress was assumed to be spatially uniform over the domain. Given the high correlations between the ASIT and METS winds, 4.5-km apart, this appears to be a reasonable assumption. Based on an analysis of the full wind and current datasets collected from MVCO, conditions in 2011 appear to be typical for the area.

\section{c. Sea surface temperature}

Advanced Very High Resolution Radiometer (AVHRR) data from National Oceanic and Atmospheric Administration (NOAA) satellites 16-19 were obtained (available online at http://tds.maracoos.org/ thredds/catalog/SST/2011/catalog.html) to estimate the spatial gradients of sea surface temperature across the radar domain. The Mid Atlantic Regional Association Coastal Ocean Observing System (MARACOOS) AVHRR data product contains 1-km spatial resolution data for the Mid-Atlantic Bight of the U.S. East Coast, to which cloud and land masks have been applied. All passes over the study area from all available satellites with more than $50 \%$ cloud-free coverage within a $30 \mathrm{~km}$ by $30 \mathrm{~km}$ area centered on the radar footprint were further examined visually for georeferencing errors. Those data with obvious or questionable referencing issues, as well as those with significant coverage gaps within the radar domain, were eliminated. Estimates of water column temperature from the hydrographic mooring attached to the ASIT tower were used to identify passes with temperatures that were considered suspect, given the differences in measurement depths. The hydrographic chain consisted of 3 Sea-Bird Electronics (SBE)-37 Microcats located at 2-, 8.5-, and 14-m depth, but only the 8.5-mdepth instrument was operational for the entire year (Fig. 3). SST passes with no coverage at ASIT, greater than $2^{\circ} \mathrm{C}$ difference during the winter months, or greater than $5^{\circ} \mathrm{C}$ difference during the summer months, were excluded from the analysis. These quality control measures reduced the dataset to 449 individual passes occurring on 189 unique days during the time period of viable surface current observations (Fig. 2).

\section{Tidal velocities}

A comparison of tidal constituents estimated from the yearlong records of depth-averaged velocity at the MVCO 12-m node ADCP and the nearby HF radar surface currents illustrate the dominant constituents of the area as well as the close correspondence between the surface and depth-averaged tides. As reported previously (Shearman and Lentz 2004; Fewings et al. 2008), the $M_{2}$ tide is by far the largest single constituent present with a magnitude of $23 \mathrm{~cm} \mathrm{~s}^{-1}$ at the node location (Table 1). While most of the largest constituents are also in the semidiurnal band $\left(N_{2}\right.$ and $S_{2}$ in addition to $\left.M_{2}\right)$, important constituents were also found in the diurnal $\left(K_{1}, O_{1}\right.$, and $\left.S_{1}\right)$ and higher frequency $\left(M_{4}, M_{6}\right)$ bands as 


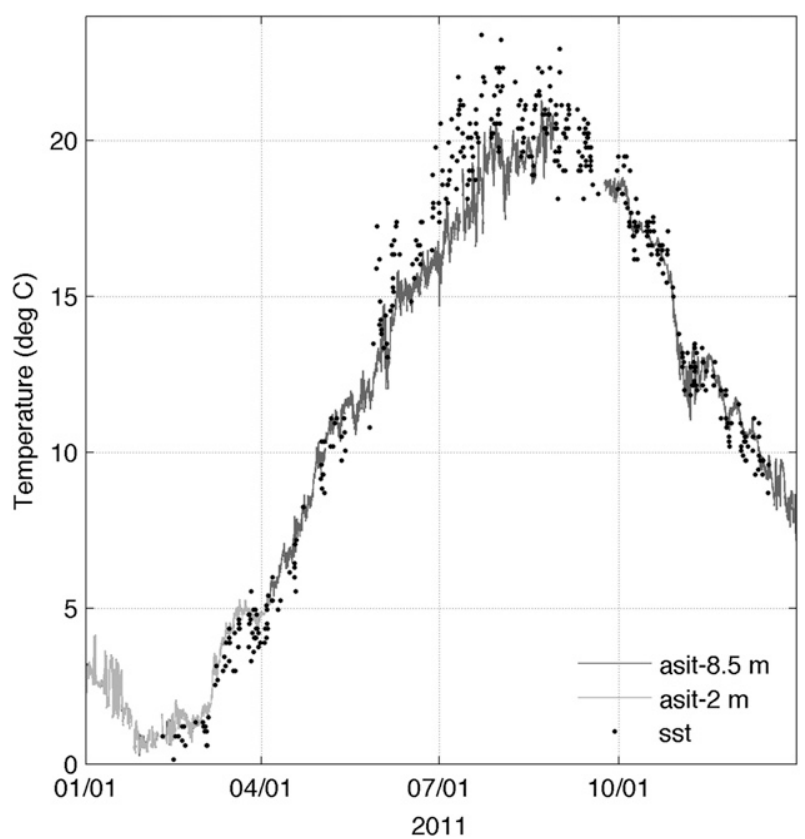

FIG. 3. In situ temperature at 2- and $8.5-\mathrm{m}$ below the water surface from the ASIT 17-m hydro-chain compared with nearby SST pixels from 449 unique SST passes of AVHRR imagery of the MVCO area. SST passes with no coverage at ASIT, greater than $2^{\circ} \mathrm{C}$ difference during the winter months or greater than $5^{\circ} \mathrm{C}$ difference during the summer months, were eliminated.

well. The constituent amplitudes and phases estimated from the radar-based surface currents- the mean of the amplitude and phase estimates from the four grid points nearest to the ADCP location-compare well with the depth-averaged ADCP results, with only small [O(5\%)] differences in amplitude and phase existing for the largest constituents. One exception to this is the $S_{1}$ constituent, which is around four times larger in magnitude at the surface, likely owing to the effects of diurnal wind forcing over the domain. Other than this, the differences between the ADCP and radar estimates generally increase as the magnitude of the constituents, and their signal-tonoise ratios (snr; not shown) decrease (Table 1). This comparison shows that, as assumed here, surface-currentbased tides appear to be an adequate proxy for the depthaveraged tidal velocities over the yearlong record.

In view of the nearby channel between the islands of Martha's Vineyard and Nantucket and the shallow regions adjacent to it, there is the potential for strong spatial gradients in both amplitudes and phases of tidal currents. Focusing on the dominant $M_{2}$ tidal constituent using the surface currents only, estimates of the tidal ellipse orientation and magnitude vary substantially across the region (Fig. 4). The $M_{2}$ constituent amplitude is strongest along the eastern edge of the domain, but ellipse orientations vary strongly along this edge and are generally oriented pointing toward the channel that runs between Martha's Vineyard and Nantucket (Fig. 1). Moving south from this eastern edge, ellipses are oriented onshore near the $20-\mathrm{m}$ isobath before transitioning to a more isotropic orientation in the southernmost portion of the domain (Fig. 4). The $M_{2}$ tides were weakest along the western edge with ellipses oriented approximately along isobaths at amplitudes of $10 \mathrm{~cm} \mathrm{~s}^{-1}$ or less. This transition from weak tidal velocities in the west to large tidal velocities in the east occurs rapidly, increasing $30 \mathrm{~cm} \mathrm{~s}^{-1}$ in amplitude over a spatial scale of less than $20 \mathrm{~km}$ (Figs. 4 and 5). The phase of the $M_{2}$ tidal constituent also varies more than $60^{\circ}$ from west to east (Fig. 5). Additional constituents in the semidiurnal band have spatial variations in amplitude and phase similar to those of the dominant $M_{2}$ tide described above, generally increasing moving eastward (Fig. 5).

The most important constituent in the diurnal band$K_{1}$ - has a markedly different spatial structure with small but variable $\left(2.5-3.5 \mathrm{~cm} \mathrm{~s}^{-1}\right)$ major axis amplitudes throughout the domain (Fig. 5). Phases for the $K_{1}$ tide were from $140^{\circ}$ to $160^{\circ}$ throughout much of the domain, but decreased to as little as $80^{\circ}$ approaching the northeast corner. The major axis of the $K_{1}$ tide was generally directed along isobath, except over the shoals along the northeast corner where it was across isobath. Representative of the higher-frequency band, the $M_{6}$ tidal constituent was generally small in amplitude but varies appreciably across the domain, rising sharply to $4 \mathrm{~cm} \mathrm{~s}^{-1}$ as the northeast corner is approached. The $M_{6}$ phases varied generally between $20^{\circ}$ and $80^{\circ}$ across the domain (Fig. 5).

The high-resolution views of tidal velocities shown here offer more detail than previous estimates of the tidal structure in the region (He and Wilkin 2006) and reveal stronger spatial variations than previously predicted, but potentially smaller maximum velocities. In an analysis of the spatial structure of tidal currents over the New England middle and outer shelf from moorings, Shearman and Lentz (2004) reported amplitude variations of approximately $5 \mathrm{~cm} \mathrm{~s}^{-1}$ across midshelf south of Martha's Vineyard and nearly constant phases. The modeling work of $\mathrm{He}$ and Wilkin also suggested that phase variations across the radar domain were small. However, the tidal currents estimated by $\mathrm{He}$ and Wilkin were stronger than those observed here, both in or near the channel and through the radar domain, likely due to the effects of model resolution on results in these inner-shelf areas, as discussed by Ganju et al. (2011).

\section{Seasonally averaged velocities}

For the mean velocity at the location of the MVCO underwater node, averaged over the entire study period, 
TABLE 1. Tidal constituents at the location of the MVCO underwater node (for T_tide-estimated constituents where snr $>2$ ).

\begin{tabular}{|c|c|c|c|c|c|c|c|}
\hline \multirow[b]{2}{*}{$\begin{array}{c}\text { Tidal } \\
\text { constituent }\end{array}$} & \multirow[b]{2}{*}{$\begin{array}{l}\text { Period } \\
\text { (h) }\end{array}$} & \multicolumn{3}{|c|}{ Depth-averaged ADCP } & \multicolumn{3}{|c|}{ HF radar surface currents } \\
\hline & & $\begin{array}{c}\text { Major axis } \\
\left(\mathrm{cm} \mathrm{s}^{-1}\right)\end{array}$ & $\begin{array}{c}\text { Minor axis } \\
\left(\mathrm{cm} \mathrm{s}^{-1}\right)\end{array}$ & Phase & $\begin{array}{c}\text { Major axis } \\
\left(\mathrm{cm} \mathrm{s}^{-1}\right)\end{array}$ & $\begin{array}{c}\text { Minor axis } \\
\left(\mathrm{cm} \mathrm{s}^{-1}\right)\end{array}$ & Phase \\
\hline \multicolumn{8}{|c|}{ Diurnal } \\
\hline$O_{1}$ & 25.82 & $1.43 \pm 0.40$ & $-0.13 \pm 0.16$ & $-71.40^{\circ} \pm 18.09^{\circ}$ & $2.15 \pm 0.68$ & $0.14 \pm 0.46$ & $-79.01^{\circ} \pm 15.79^{\circ}$ \\
\hline$P_{1}$ & 24.07 & $0.72 \pm 0.43$ & $-0.04 \pm 0.17$ & $-73.05^{\circ} \pm 31.83^{\circ}$ & $0.58 \pm 0.46$ & $0.36 \pm 0.46$ & $74.30^{\circ} \pm 91.77^{\circ}$ \\
\hline$S_{1}$ & 24.00 & $0.45 \pm 0.47$ & $-0.08 \pm 0.22$ & $16.11^{\circ} \pm 80.68^{\circ}$ & $1.99 \pm 0.72$ & $-0.04 \pm 0.73$ & $1.05^{\circ} \pm 20.08^{\circ}$ \\
\hline$K_{1}$ & 23.93 & $3.04 \pm 0.40$ & $-0.31 \pm 0.14$ & $-60.86^{\circ} \pm 8.33^{\circ}$ & $3.48 \pm 0.63$ & $0.03 \pm 0.48$ & $-56.00^{\circ} \pm 10.00^{\circ}$ \\
\hline \multicolumn{8}{|c|}{ Semidiurnal } \\
\hline$N_{2}$ & 12.66 & $4.71 \pm 0.41$ & $-0.71 \pm 0.16$ & $-8.13^{\circ} \pm 4.89^{\circ}$ & $5.07 \pm 0.69$ & $-0.84 \pm 0.47$ & $1.03^{\circ} \pm 7.26^{\circ}$ \\
\hline $\mathrm{NU}_{2}$ & 12.63 & $1.38 \pm 0.44$ & $-0.21 \pm 0.14$ & $4.40^{\circ} \pm 15.33^{\circ}$ & $1.53 \pm 0.65$ & $-0.22 \pm 0.45$ & $0.83^{\circ} \pm 24.55^{\circ}$ \\
\hline$M_{2}$ & 12.42 & $22.66 \pm 0.39$ & $-3.05 \pm 0.14$ & $26.44^{\circ} \pm 1.15^{\circ}$ & $23.46 \pm 0.64$ & $-3.73 \pm 0.47$ & $31.82^{\circ} \pm 1.87^{\circ}$ \\
\hline$M K S_{2}$ & 12.39 & $0.69 \pm 0.41$ & $-0.12 \pm 0.19$ & $10.30^{\circ} \pm 35.58^{\circ}$ & $0.95 \pm 0.57$ & $0.21 \pm 0.52$ & $-25.99^{\circ} \pm 36.58^{\circ}$ \\
\hline$L_{2}$ & 12.19 & $2.08 \pm 0.49$ & $-0.21 \pm 0.15$ & $67.58^{\circ} \pm 14.02^{\circ}$ & $2.15 \pm 0.76$ & $-0.46 \pm 0.53$ & $70.65^{\circ} \pm 23.75^{\circ}$ \\
\hline$S_{2}$ & 12.00 & $3.07 \pm 0.38$ & $-0.51 \pm 0.12$ & $51.36^{\circ} \pm 8.04^{\circ}$ & $3.55 \pm 0.64$ & $-0.50 \pm 0.43$ & $59.20^{\circ} \pm 10.97^{\circ}$ \\
\hline$K_{2}$ & 11.97 & $0.84 \pm 0.37$ & $-0.14 \pm 0.16$ & $59.04^{\circ} \pm 28.86^{\circ}$ & $1.17 \pm 0.66$ & $-0.01 \pm 0.44$ & $58.75^{\circ} \pm 33.87^{\circ}$ \\
\hline \multicolumn{8}{|c|}{ Higher frequencies } \\
\hline $\mathrm{MO}_{3}$ & 8.39 & $0.42 \pm 0.17$ & $0.02 \pm 0.07$ & $25.44^{\circ} \pm 20.26^{\circ}$ & $0.32 \pm 0.21$ & $-0.08 \pm 0.21$ & $37.53^{\circ} \pm 48.05^{\circ}$ \\
\hline$M_{3}$ & 8.28 & $0.17 \pm 0.15$ & $-0.01 \pm 0.09$ & $-76.61^{\circ} \pm 51.84^{\circ}$ & $0.23 \pm 0.18$ & $-0.13 \pm 0.18$ & $-89.18^{\circ} \pm 85.23^{\circ}$ \\
\hline$M K_{3}$ & 8.18 & $0.47 \pm 0.15$ & $-0.08 \pm 0.08$ & $60.04^{\circ} \pm 21.91^{\circ}$ & $0.37 \pm 0.22$ & $-0.01 \pm 0.21$ & $51.27^{\circ} \pm 35.38^{\circ}$ \\
\hline$M_{4}$ & 6.21 & $0.72 \pm 0.12$ & $0.18 \pm 0.07$ & $-29.03^{\circ} \pm 11.02^{\circ}$ & $0.31 \pm 0.17$ & $0.16 \pm 0.18$ & $-55.51^{\circ} \pm 53.58^{\circ}$ \\
\hline $2 M K_{5}$ & 4.93 & $0.30 \pm 0.08$ & $0.04 \pm 0.05$ & $-85.41^{\circ} \pm 18.78^{\circ}$ & $0.22 \pm 0.10$ & $0.12 \pm 0.09$ & $1.25^{\circ} \pm 71.86^{\circ}$ \\
\hline$M_{6}$ & 4.14 & $1.39 \pm 0.17$ & $-0.05 \pm 0.04$ & $37.45^{\circ} \pm 6.84^{\circ}$ & $0.72 \pm 0.12$ & $0.27 \pm 0.08$ & $41.87^{\circ} \pm 9.47^{\circ}$ \\
\hline
\end{tabular}

there is a small $5 \mathrm{~cm} \mathrm{~s}^{-1}$ along-shelf (westward) velocity and smaller offshore flow in the long-term depthaveraged mean (Fewings 2007; Lentz et al. 2008). This is also true for the near-surface ADCP-based velocities. However, when an estimate of the Stokes drift owing to surface gravity waves is added to the measured ADCP velocity to make a more accurate comparison to the radar (Kirincich et al. 2012), the mean across-shelf flow near the surface becomes slightly onshore (Fig. 6). With this adjustment, the ADCP-based surface vector is similar to nearby radar-based estimates of the mean surface current. Standard errors for the mean values of surface currents for the 11-month record were less than $0.1 \mathrm{~cm} \mathrm{~s}^{-1}$ across the study area. Moving away from the node location, mean current directions and magnitudes quickly depart from the values seen at the node. The westward currents at the location of the node are part of an eddylike recirculation structure that has its strongest velocities $\left(10-12 \mathrm{~cm} \mathrm{~s}^{-1}\right)$ to the east and south, close to the bathymetric shoals on the eastern side of the domain. The center of the eddy feature is located near $41^{\circ} 19^{\prime} \mathrm{N}$, $70^{\circ} 33^{\prime} \mathrm{W}$ just south and east of ASIT, where mean surface currents are near zero. The eddy structure resembles that found in the model results of Ganju et al. (2011). Mean currents along the southern edge of the radar domain are directed approximately westward, although some appear to turn north and east to feed the strong northeastward mean flows seen along the eastern edge.
Mean currents in the western and northwestern sides of the domain are quite weak, only $1-2 \mathrm{~cm} \mathrm{~s}^{-1}$, and variable in direction. It is noteworthy that the mean circulation in the middle of the domain is along-shelf to the east, the opposite of mean currents both to the north and south.

With the strong seasonal changes in hydrography that occur over the New England shelf and previous reports of seasonally variable mean currents at the MVCO underwater node (Fewings et al. 2008), the average surface currents during winter and summer were examined to document the seasonal variability of the spatial pattern described above. Weakly stratified conditions characteristic of winter (Fewings et al. 2008), defined here as December-March, were compared to stratified conditions characteristic of summer, defined as June-September.

In winter, the spatial structure of the mean surface currents was markedly different than the annual mean (Fig. 7). While the northeast jet was still present along the eastern side, currents were weak and westward near the node and weak and eastward across the southern edge, both in contrast to the annual mean. Currents in the northwest portion of the domain during winter were eastward and stronger than in the annual mean. Surface currents in the central part of the domain, offshore of the location of ASIT are directed to the south or southwest with velocities reaching $5 \mathrm{~cm} \mathrm{~s}^{-1}$. 


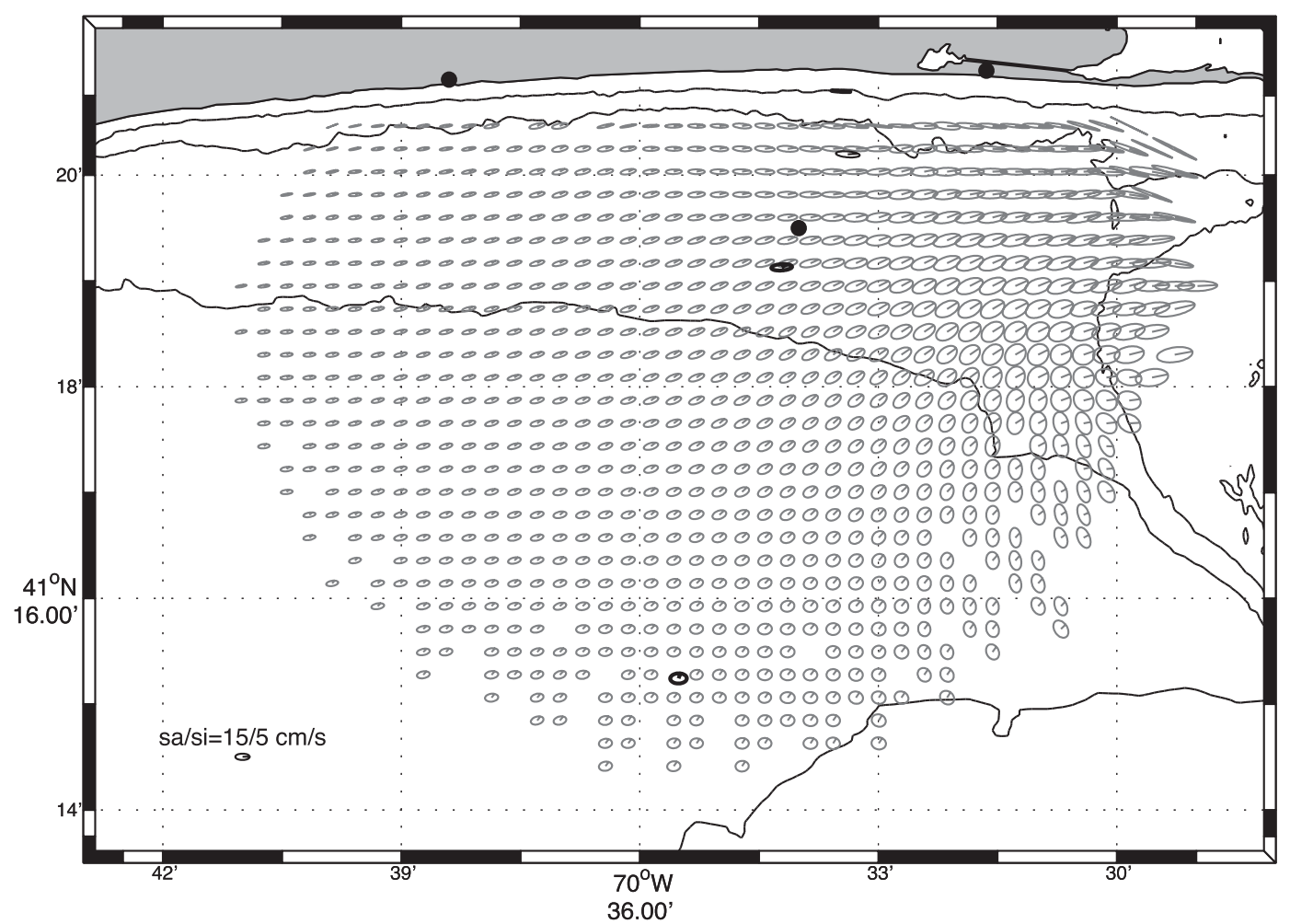

FIG. 4. Tidal ellipses of the $M_{2}$ constituent for HF radar surface currents observed (gray) and near-surface currents obtained from concurrent ADCP observations by MVCO and historic ADCP data from the SWWIM array (black) in 7, 12, 17, and $27 \mathrm{~m}$ of water. The 5-, 10-, 20-, and 30-m isobaths are shown along with a reference ellipse having semimajor/semiminor ( $\mathrm{sa} / \mathrm{si})$ axis of $15 / 5 \mathrm{~cm} \mathrm{~s}^{-1}$.

In contrast to winter, the spatial pattern of mean surface currents during the summer months (Fig. 7) was more similar to the annual mean shown in Fig. 6. In summer, surface currents were positive and westward along both the south and north boundaries and stronger than the annual mean, as was the strength of the northeastward jet and recirculation to the south of ASIT (Fig. 7). In both seasons, surface currents near the location of the underwater node agree well with the nearsurface velocities measured by the ADCP (not shown). Mean wind stress was to the east at $0.04 \mathrm{~Pa}$ during winter and $0.02 \mathrm{~Pa}$ to the north-northeast during summer. Thus, a portion of the differences between summer and winter mean circulation might be explained by differences in the mean winds.

\section{SST anomalies and the advective heat flux divergence}

Mean SST anomalies highlight the seasonal differences of the observed hydrographic structure and suggest a role of the background circulation in causing the variability seen. For all satellite overpasses meeting our qualitycontrol criteria, SSTs within a box surrounding the domain of the radar system coverage were differenced from the mean temperature of each pass and averaged in time to create mean SST anomaly fields for the same time periods of the seasonal mean currents (Fig. 7). During winter, SST anomalies warm moving offshore, and contours of SST anomaly generally coincide with lines of bathymetry, except near the location of the northeastward jet (Fig. 7). Summer SST anomalies have a much different spatial structure. The total temperature change across the region is stronger in summer, up to $0.5^{\circ} \mathrm{C}$ with isotherms more closely spaced in the middle of the domain (Fig. 7). The orientation of this front changes throughout the domain, with the zero anomaly contour (Fig. 7, black line) being east-west in orientation in the northeast corner, north-south in orientation in the middle of the domain, and approximately eastwest again in the southwest corner. As a result, an across-shelf temperature gradient of up to $0.35^{\circ} \mathrm{C}$ over $3 \mathrm{~km}$ exists along $70^{\circ} 32^{\prime} \mathrm{W}$, while an along-shelf gradient of up to $0.35^{\circ} \mathrm{C}$ over $6 \mathrm{~km}$ exists along $41^{\circ} 19^{\prime} \mathrm{N}$.

The spatial structures of the background circulation and SST anomalies found during winter and summer contain evidence of the potentially important role of advective heat flux divergence in the overall heat balance 


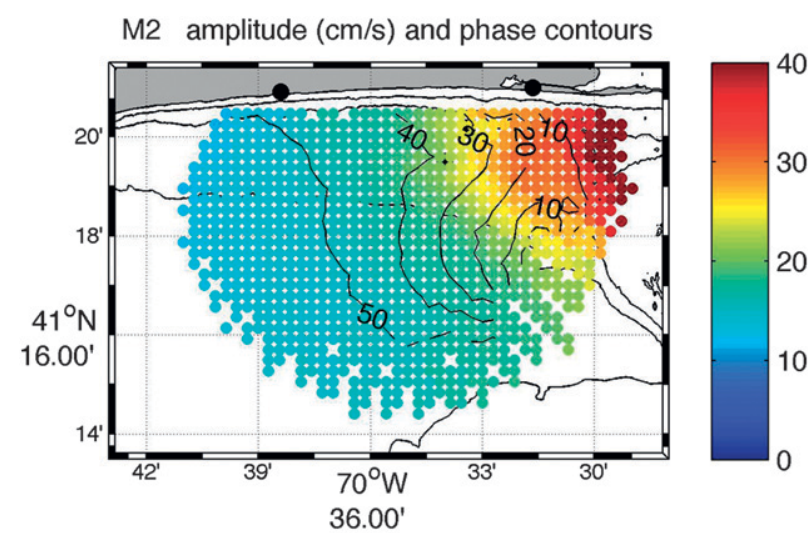

$\mathrm{K} 1$ amplitude $(\mathrm{cm} / \mathrm{s})$ and phase contours

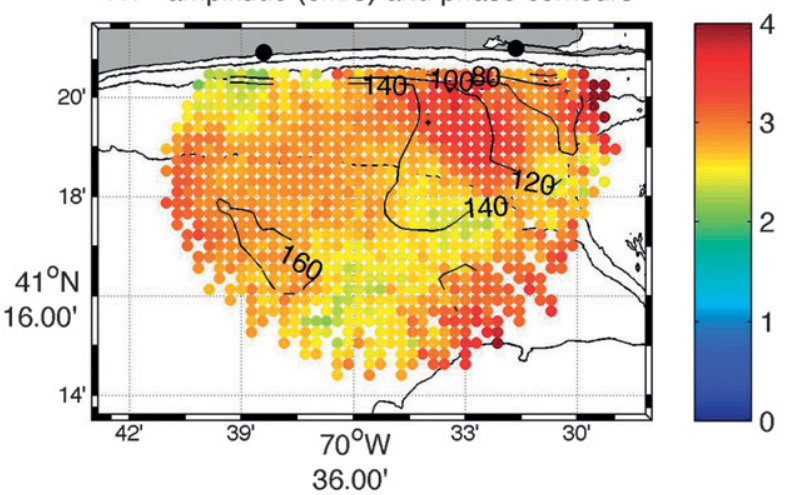

M6 amplitude $(\mathrm{cm} / \mathrm{s})$ and phase contours

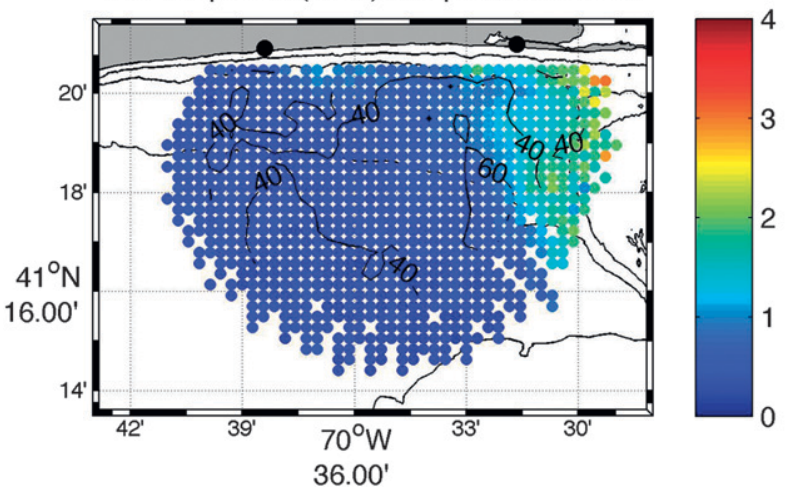

FIG. 5. Amplitudes (colors, $\mathrm{cm} \mathrm{s}^{-1}$ ) and relative phases $\left({ }^{\circ}\right)$ of the HF radar-estimated (top) $M_{2}$, (middle) $K_{1}$, and (bottom) $M_{6}$ constituents. In each panel, contours of the relative phase distribution are superimposed on top of the amplitude of the semimajor axis.

of the region. SST anomaly contours during winter generally align with lines of constant bathymetry, consistent with a 1D heat balance, driven by cooling of the surface waters through a loss of heat to the atmosphere and convective mixing of the water column (Fewings and Lentz 2011). In a 1D balance and spatially constant surface heat flux out of the ocean, shallower waters will attain colder temperatures as the mass of the water column being cooled, only a function of water depth, is

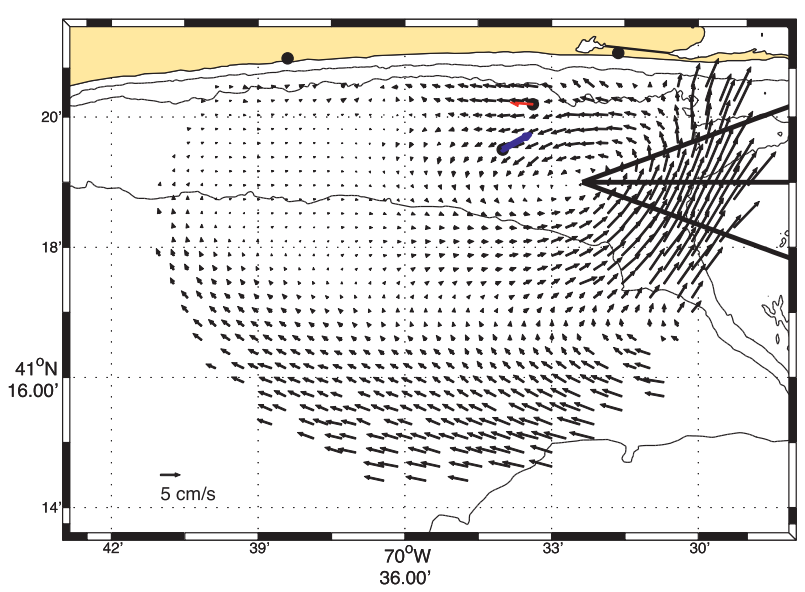

FIG. 6. The mean surface currents for the study period, FebruaryDecember 2011, along with the near-surface ADCP-based velocity vector at the location of the MVCO underwater node (red). Locations of the three radar stations (dots) are shown, as is the direction of the mean wind stress (blue arrow). The across-shelf lines used to test the correspondence of the observed northeastward jet to the Loder (1980) model of tidal rectification are shown emanating from the center of the recirculation region at bearing angles of $70^{\circ}, 90^{\circ}$, and $110^{\circ} \mathrm{T}$.

smaller. However, in the area of the northeastward jet, an area of strong advection, SST anomaly contours during winter tend to diverge from isobaths (Fig. 7). The potential effect of surface currents on the heat balance can be illustrated by computing the mean and timevarying advective heat flux divergence. The mean AHF divergence was estimated directly from the mean SST anomaly pattern and the mean velocity, spatially averaged to the $1-\mathrm{km}$ resolution of the SST imagery. The time-varying AHF divergence was estimated as the product of the SST anomaly gradients from each SST pass and the corresponding residual surface currents from the time of the pass, averaged over the time period in question.

For the winter period, both the mean and timevarying along- $(u d T / d x)$ and across-shelf $(v d T / d y)$ advective heat flux divergences are shown in Fig. 8 along with the total AHF divergence integrated over a 100-day period to highlight the potential seasonal-scale changes in surface temperature owing to the surface AHF. The most significant mean advective heat flux gain or loss is seen in the area of the northeastward jet. Here, as the mean jet velocities advect warmer waters from offshore northward, the jet causes a net increase or gain of heat in the area east of $70^{\circ} 33^{\prime} \mathrm{W}$. The spatially averaged AHF gain in this area is $8^{\circ} \mathrm{C}$ over the 100 -day period. Interestingly, the time-varying AHF divergence acts to offset much of that mean AHF gain, generally acting to remove heat in the area of the northeastward jet, with average values of $-5^{\circ} \mathrm{C}$ over the 100 -day period. The 

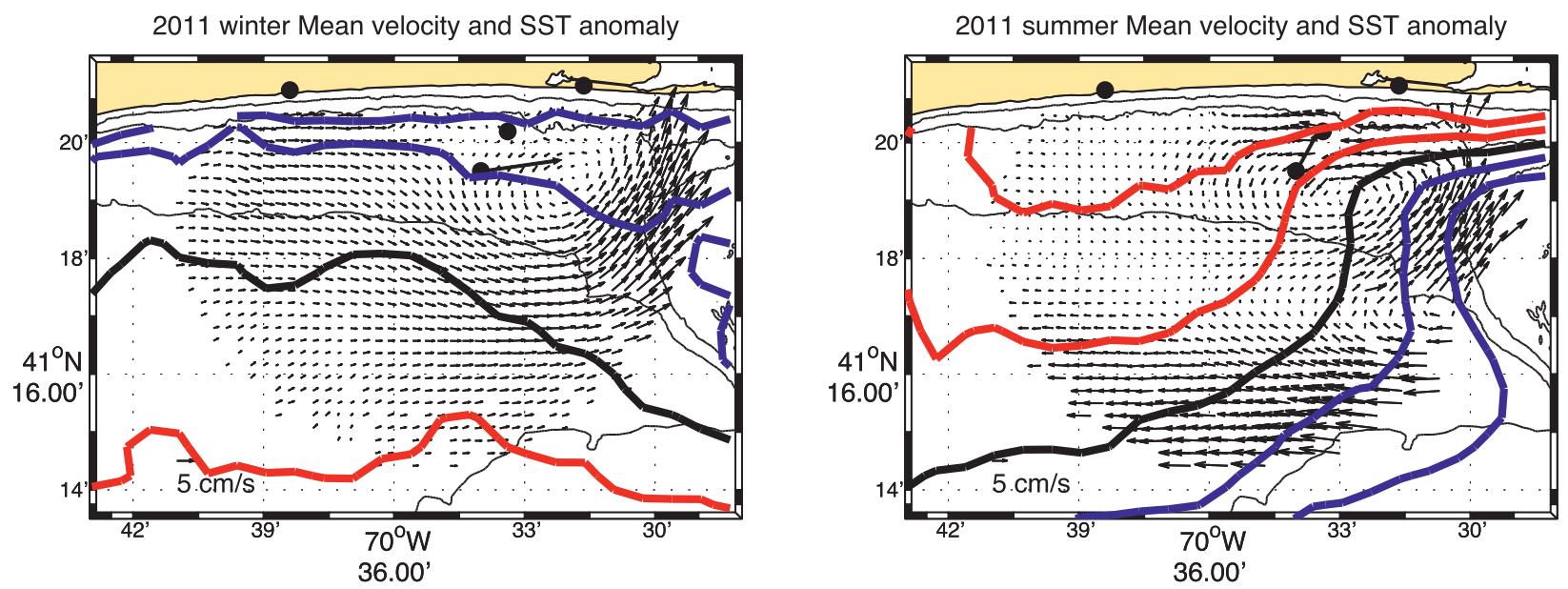

FIG. 7. Mean surface currents for (left) winter (February-December) and (right) summer (June-September) periods during 2011. The mean SST anomaly relative to the space-time average for each season is shown for the $-0.25^{\circ}$ and $-0.1^{\circ}$ (blue), $0^{\circ}$ (black), $0.1^{\circ}$ and $0.25^{\circ} \mathrm{C}$ (red) contours. The direction of the seasonally averaged wind stress (black arrow) is shown at the location of ASIT.

time-varying $\mathrm{AHF}$ divergence west of $70^{\circ} 33^{\prime} \mathrm{W}$ is generally small-the spatial average in this area is near zero-but variable in magnitude.

During summer, the SST anomaly pattern exhibits spatial gradients much sharper than those found in winter both in the along- and across-shelf directions (Fig. 7). The areas of the strongest mean currents appear to play a critical role in the spatial pattern of the observed SST. Inshore, the strongest along-shelf velocities exist where the across-shelf gradient of SST is sharpest, indicating that a thermal-wind balance might also explain a portion of the mean velocity structure found. To the west, these velocities weaken and/or turn offshore, likely creating the bulge of warmer waters observed to the west.

An examination of the mean and time-varying along$(u d T / d x)$ and across-shelf $(v d T / d y)$ advective heat flux divergences for the summer period (Fig. 9) shows the implications of the variable circulation on SST anomalies. The along-shelf jets that exist in the summertime mean circulation, combined with the mean SST anomaly gradient, lead to significant mean AHF divergences on the eastern side of the study area. AHF losses occur in
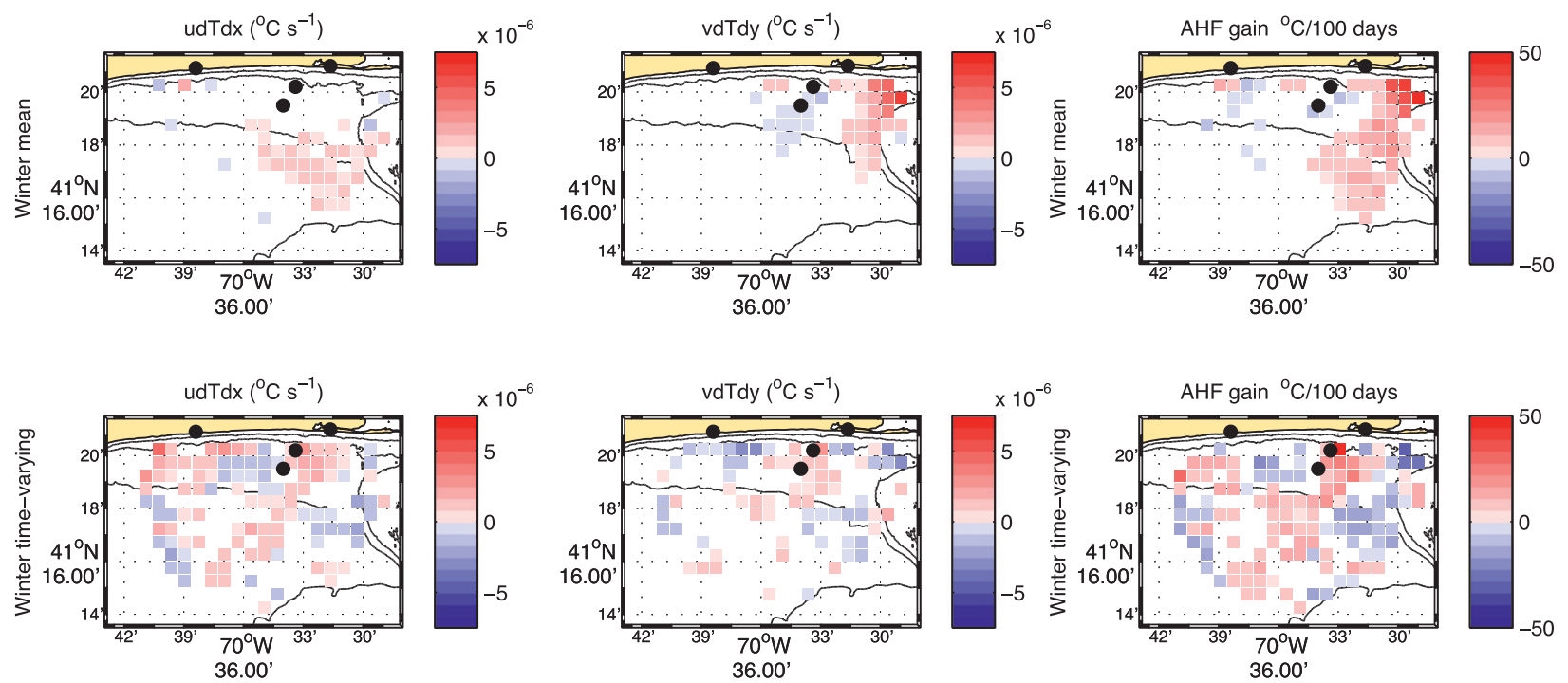

FIG. 8. Estimated AHF divergences for winter: (from top left to right) the along- ( $u d T / d x)$ and across-shelf ( $v d T / d y)$ AHF divergences owing to the mean velocity and mean SST anomaly gradients and the total mean AHF gain/loss integrated over a 100-day period. (from bottom left to right) The time-varying along- $(u d T / d x)$ and across-shelf $(v d T / d y)$ AHF divergences and the total time-varying AHF gain/loss integrated over a 100-day period. Divergence values less than $5 \times 10^{-7}{ }^{\circ} \mathrm{Cs}^{-1}$ below the estimated noise level are not shown. 

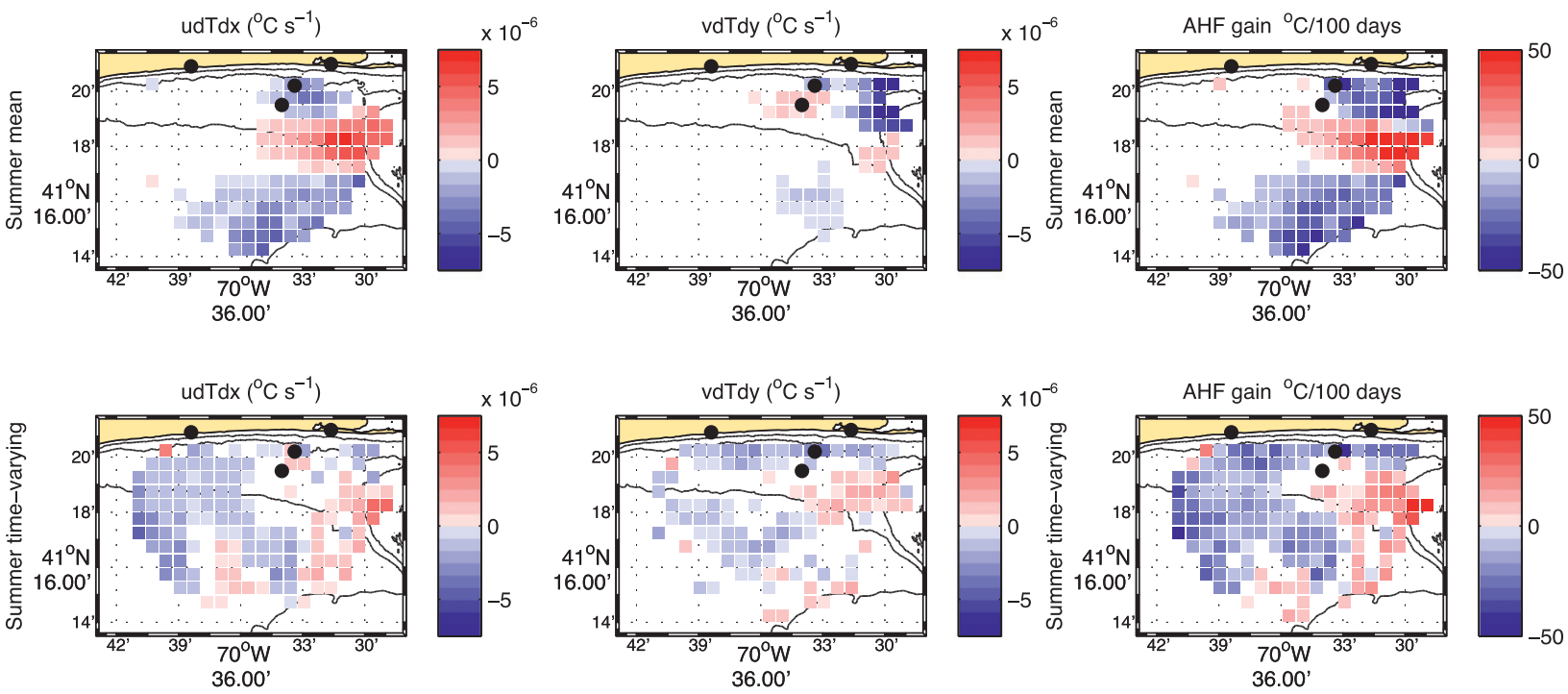

FIG. 9. As in Fig. 8, but for summer.

both in- and offshore westward jets, as westward currents advect cooler waters. The spatial average of the total heat loss attributed to the divergence of $\mathrm{AHF}$ over a 100-day period (Fig. 9) is $26^{\circ} \mathrm{C}$ for the inshore jet and $18^{\circ} \mathrm{C}$ for the offshore jet. The southern side of the recirculation advects warmer waters eastward, providing an average of $14^{\circ} \mathrm{C}$ of heat gain over the 100 -day period.

The time-varying AHF divergence during summer also has a heat gain in the area of the northeastward jet offshore of $41^{\circ} 19^{\prime} \mathrm{N}$ east of $70^{\circ} 33^{\prime} \mathrm{W}$, leading to an average gain of $11^{\circ} \mathrm{C}(100 \text { days })^{-1}$. Perhaps most notably, the summertime-varying AHF divergence leads to significant AHF losses over a broad area both inshore and to the west of $70^{\circ} 33^{\prime} \mathrm{W}$. For the area west of $70^{\circ} 33^{\prime} \mathrm{W}$, this represents a spatially averaged cooling of $12^{\circ} \mathrm{C}$ in a region where the mean AHF divergences are near zero, and thus provides all of the AHF-based cooling outside of the areas of the along-shelf jets. For comparative purposes, the amount of air-sea heat flux into the water column over a similar 100-day period during summer has the potential to raise the temperature of the mixed layer by up to $40^{\circ} \mathrm{C}$ (Fewings and Lentz 2011). The implications of this on the total heat balance will be discussed later.

\section{Estimating terms in the mean momentum equations}

The remainder of the analysis investigates the role of tidal stresses on the annual mean momentum balances by utilizing the surface currents to estimate terms in the depth-averaged, tidally averaged momentum equations. The depth average of all terms in the east $(x, u)$ and north $(y, v)$ momentum equations, oriented approximately along and across shelf, respectively, using continuity to recast the advective terms as the flux divergences, can be written as

$\frac{\partial u}{\partial t}+\frac{1}{H}\left(\frac{\partial u u H}{\partial x}+\frac{\partial u v H}{\partial y}\right)-f v=-\frac{1}{\rho_{o}} \frac{\partial P}{\partial x}+\frac{\tau_{x}^{s}-\tau_{x}^{b}}{\rho H} \quad$ and

$\frac{\partial v}{\partial t}+\frac{1}{H}\left(\frac{\partial u v H}{\partial x}+\frac{\partial v v H}{\partial y}\right)+f u=-\frac{1}{\rho_{o}} \frac{\partial P}{\partial y}+\frac{\tau_{y}^{s}-\tau_{y}^{b}}{\rho H}$,

where $\tau^{s}$ and $\tau^{b}$ are the surface (wind) and bottom stresses, $H$ is the total water depth, $f$ is the Coriolis parameter, $\rho_{o}=1025 \mathrm{~kg} \mathrm{~m}^{-3}$ is a reference density, and $P$ is the depth-averaged pressure. Decomposing the velocities into tidal $(U, V)$ and subtidal or low frequency $(\bar{u}, \bar{v})$ components, as $u=\bar{u}+U$, and averaging over many tidal cycles gives the steady momentum equations:

$$
\begin{aligned}
& \frac{1}{H}\left(\frac{\partial \bar{u} \bar{u} H}{\partial x}+\frac{\partial \bar{u} \bar{v} H}{\partial y}\right)+\frac{1}{H}\left(\frac{\partial \overline{U U} H}{\partial x}+\frac{\partial \overline{U V} H}{\partial y}\right) \\
& -f \bar{v}+\frac{\overline{-\tau_{x}^{s}}+\overline{\tau_{x}^{b}}}{\rho_{o} H}=-\frac{1}{\rho_{o}} \frac{\partial \bar{P}}{\partial x} \text { and } \\
& \frac{1}{H}\left(\frac{\partial \bar{u} \bar{v} H}{\partial x}+\frac{\partial \bar{v} \bar{v} H}{\partial y}\right)+\frac{1}{H}\left(\frac{\partial \overline{U V} H}{\partial x}+\frac{\partial \overline{V V} H}{\partial y}\right) \\
& \quad+f \bar{u}+\frac{-\overline{\tau_{y}^{s}}+\overline{\tau_{y}^{b}}}{\rho_{o} H}=-\frac{1}{\rho_{o}} \frac{\partial \bar{P}}{\partial y} .
\end{aligned}
$$

As shown, Eqs. (3) and (4) are written with all terms that can be estimated with the data available on the left-hand 
side and the unknown pressure gradients on the righthand side. Mean bottom stresses were estimated using the temporal average of the raw half-hour surface currents, to include the effects of the large tidal velocities on the mean bottom stress, and a drag coefficient of $1.5 \times 10^{-3}$, estimated for a depth 3-m above the bottom at the MVCO node by Kirincich et al. (2010). Each of the advective terms includes contributions from both bathymetric and advective divergence, as (for example):

$$
\frac{1}{H} \frac{\partial \bar{u} \bar{u} H}{\partial x}=\left(\frac{1}{H} \bar{u} \frac{\partial H}{\partial x}+\frac{\partial \bar{u} \bar{u}}{\partial x}\right)
$$

Throughout much of the domain, the bathymetric divergence was the smaller of the two components and not critical to the spatial patterns observed. However, for completeness, the sum of both components-that is, the total momentum within brackets-are presented in the analysis that follows.

Momentum results less than $\pm 1 \times 10^{-7} \mathrm{~m} \mathrm{~s}^{-2}$ were excluded from the analysis based on standard error estimates of the noise levels for the advective and Coriolis momentum terms. The representativeness of the mean surface currents for the depth-averaged, steady velocities and tidal stresses is likely to be the largest source of error in the momentum balance calculation presented. To quantify this potential error, we examined the mean vertical structure of velocity profiles from the 12 -m node ADCP obtained during the study period and the structure of the three SWWIM moorings in 7, 17, and $27 \mathrm{~m}$ of water from a similar time period in 2009. Despite the nonoverlapping time period of the SWWIM dataset, the results shown here were representative of the full threeyear dataset, and thus likely to be representative of the mean conditions present at these locations during the study period as well. Figure 10 shows the vertical structure of the mean velocities and tidal velocity products for each mooring location, along with their depth average and the mean surface currents for each of the three offshore sites.

Differences between the near-surface velocities and the depth-averaged velocities along the dominant axis of flow ranged from $\sim 1 \mathrm{~cm} \mathrm{~s}^{-1}$ or less onshore to $\sim 2 \mathrm{~cm} \mathrm{~s}^{-1}$ offshore at SWWIM-27 (Fig. 10). In contrast, differences between the ADCP near-surface and depthaveraged northward velocity were more variable and the depth averages themselves were closer to zero for the onshore stations. The mean surface currents were consistent with the near-surface vertical structure of the velocity profiles when the effects of wind-driven shear in the upper portion of the water column are included. As mean winds were to the east and north in both years (Fig. 6), surface velocities are expected to be eastward relative to the near-surface ADCP velocities. As a result, the mean surface currents were more similar to the depth average than the near-surface ADCP observations at the node-12 and SWWIM-27 sites, and only at SWWIM-17 did the surface current differ significantly from the depth-averaged eastward mean (Fig. 10).

The annually averaged tidal product magnitudes $\overline{U U}$, $\overline{V V}$, and $\overline{U V}$ for the four mooring locations are shown in the bottom rows of Fig. 10. In general, the near-surface ADCP-based estimates of $\overline{U U}$ and $\overline{V V}$ exceeded the depth-averaged values by a maximum of $\sim 1\left(\mathrm{~cm} \mathrm{~s}^{-1}\right)^{2}$ or $\sim 30 \%$, but tended to be more similar to the depthaveraged values moving offshore. For the $\overline{U V}$ term, the depth averages were half of the near-surface values for the node 12-m and SWWIM-17 sites. Both depth-average surface values were close to zero at SWWIM 27 (Fig. 10). Surface current estimates were similar to the depth averages for SWWIM 27, but overestimate the depth-averaged $\overline{U U}$ and $\overline{V V}$ inshore by up to $\sim 30 \%$. The poorest agreement comes for the $\overline{U V}$ term, with differences of up to $50 \%$ inshore.

Thus, the surface currents were generally representative of the sign and magnitude of the depth-averaged mean velocities and tidal products except when the depth average itself was weak or when significant nearsurface shear existed. It should be noted that the correspondence of the annual-mean surface velocities to the depth-averaged ADCP annual means was stronger than the correspondence of seasonal-mean surface and depth-averaged ADCP velocities. While weaker levels of vertical shear generally existed in the winter ADCP vertical profiles, the strong eastward winds found during winter led to much larger disagreements between the HF radar surface currents and the depth-averaged velocities from the ADCP. For summer averages, despite weaker winds, the vertical shear of the circulation was large enough to render the near-surface values unrepresentative of the depth-averaged mean. Weaker velocities, and poorer results, were directed north-south in the onshore mooring results shown. However, the dominant flow component was oriented more across shelf at the offshore moorings, and thus the Coriolis term based on the near-surface northward velocity component was more likely to be representative of the depth-average value. Maximum errors for the wind stress and bottom stress were also likely to be higher than the $\pm 1 \times 10^{-7} \mathrm{~m} \mathrm{~s}^{-2}$ threshold used here, due to the assumptions used to estimate these terms.

\section{Momentum balance results}

The spatial structure of terms in the along-shelf momentum balance, as they appear written on the lhs of Eq. (3), is shown in Fig. 11. The mean advective terms 

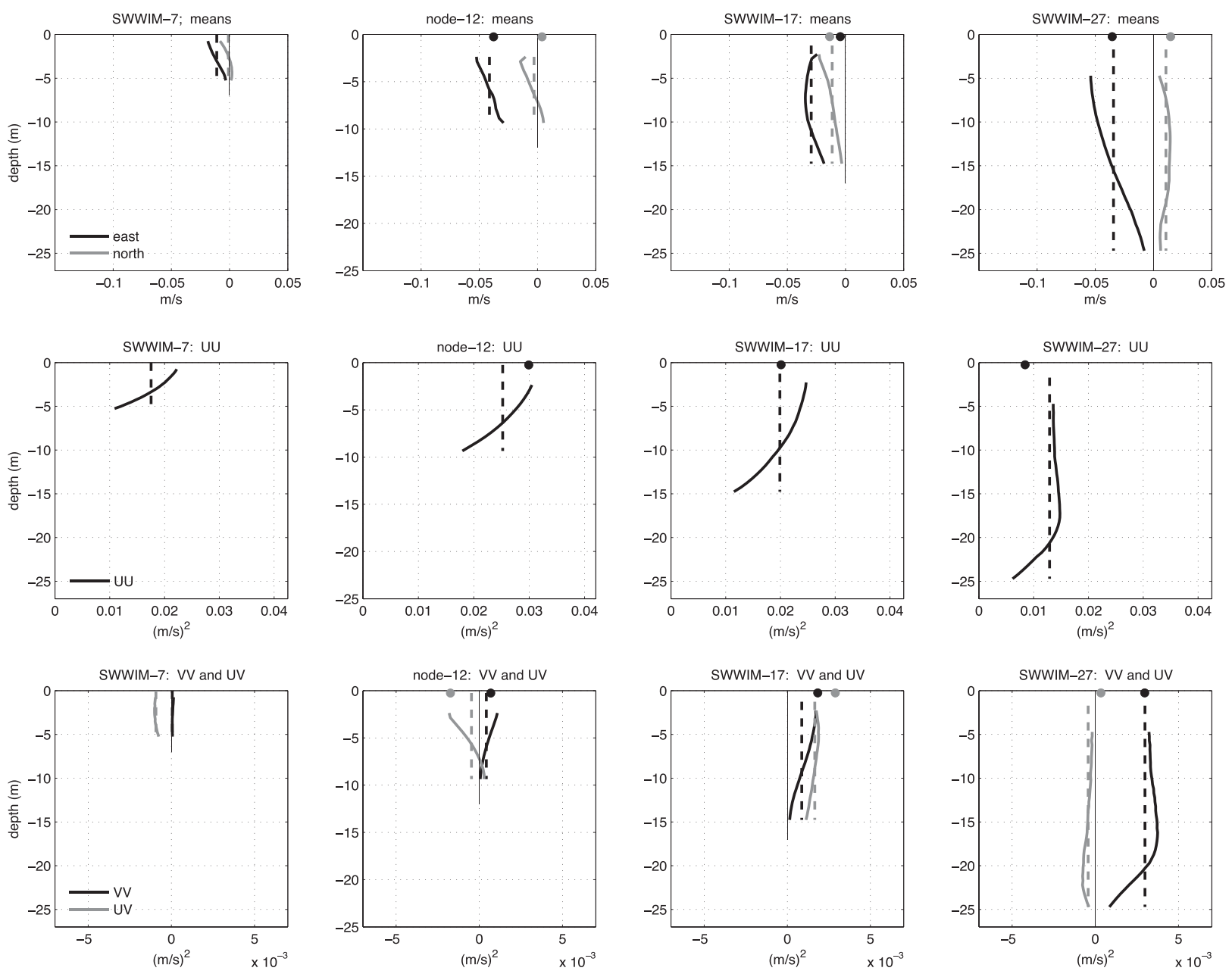

FIG. 10. Annually averaged vertical structure (solid lines) and depth average (vertical dashed lines) of the (top) east and north velocities, (middle) $\overline{U U}$, and (bottom) $\overline{V V}$ and $\overline{U V}$ tidal components at four locations within the study area (from left to right): SWWIM 7, the MVCO node, SWWIM 17, and SWWIM 27. While the data from the MVCO node were taken from the same 11-month study period as the radar surface currents, the SWWIM data shown were for a similar time span in 2009. See the tidal ellipses in Fig. 4 for the approximate locations of these moored observations. In each panel, black and/or gray dots at $-0.5-\mathrm{m}$ depth denote the 2011 average velocity or tidal products from the nearest HF radar grid point. The larger discrepancy between the mean radar surface currents and the mean near-surface ADCP velocities (top) are likely due to near-surface shear driven by the mean wind stresses, directed to the northeast.

were generally not greater than $1 \times 10^{-6} \mathrm{~m} \mathrm{~s}^{-2}$ and were small compared to tidal stresses across much of the domain. The Coriolis term was positive in a narrow portion centered along $41^{\circ} 19^{\prime} \mathrm{N}$, up to $2.5 \times 10^{-6} \mathrm{~m} \mathrm{~s}^{-2}$, negative offshore, and strongly negative in the northeastern corner. The combined wind stress and bottom stress, where spatial variations were due to a combination of shoaling bathymetry and larger tidal velocities, were mostly positive over the domain (Fig. 11). Tidal stresses were large in the eastern half of the domain and onshore, with values up to $\pm 10 \times 10^{-6} \mathrm{~m} \mathrm{~s}^{-2}$, but decrease in magnitude to the south and west. The across-shelf tidal stress strengthens to the east and was negative inshore and positive offshore. The along-shelf tidal stress was positive over much of the domain, with the exception of the southeast corner, and had significant $2-4 \mathrm{~km}$ lengthscale variability throughout.

In the across-shelf momentum balance (Fig. 12), the advective terms were again small and often not greater than the noise/error threshold. The Coriolis term was large throughout the area with strong positive values, corresponding to eastward flow, in the middle of the domain but strong negative values (from westward flow) both in- and offshore. The combined wind stress and bottom stress was mostly positive over the domain but weak in water depths greater than $15 \mathrm{~m}$. Tidal stresses were again large in the eastern half of the domain and onshore. The across-shelf tidal stress was mostly 

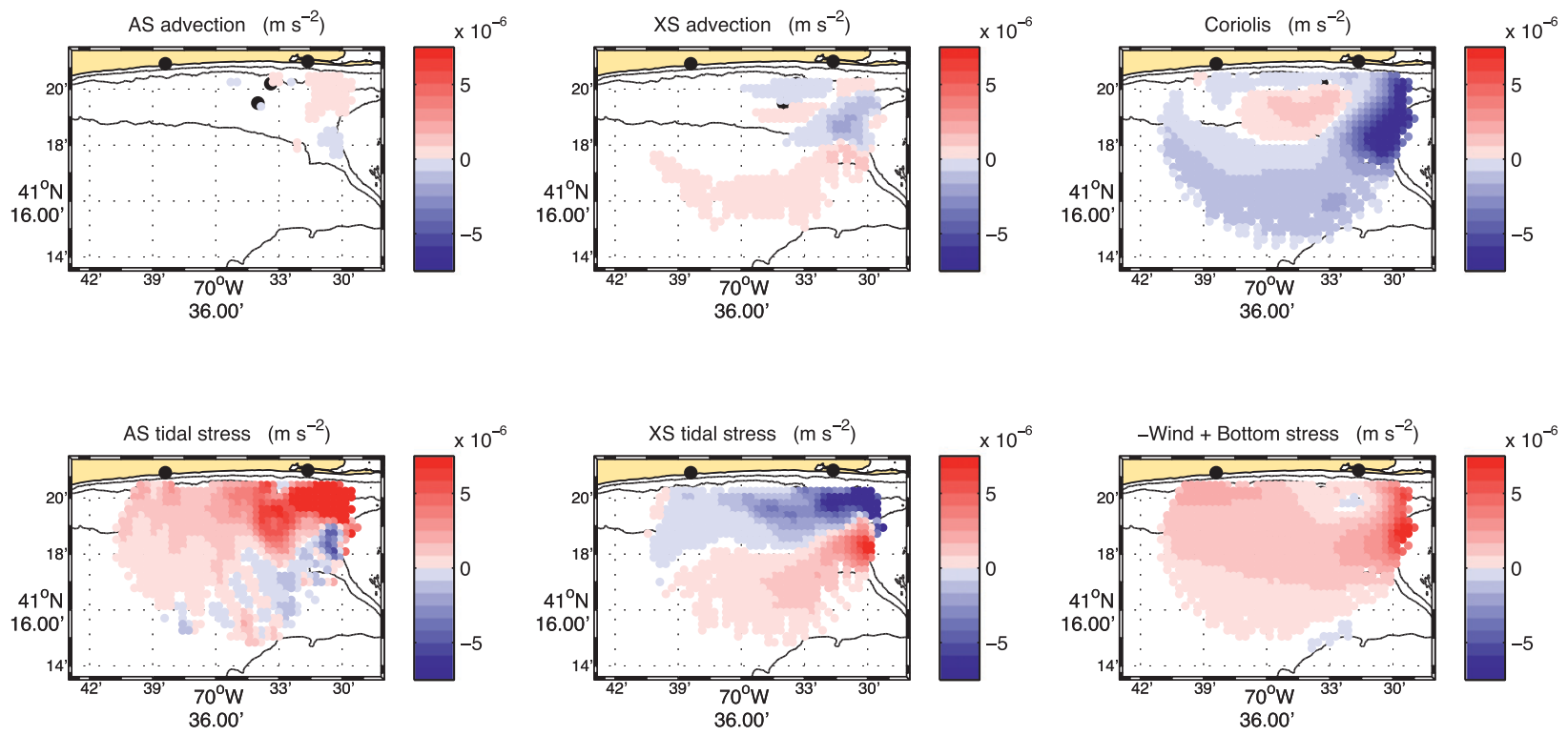

FIG. 11. Terms in the along-shelf momentum balance $\left(\mathrm{m} \mathrm{s}^{-2}\right)$, as in Eq. (3), based on the mean velocity and wind stress for the full 11-month study period: (clockwise from upper left) the AS and XS advection of along-shelf momentum, the Coriolis term, wind stress plus bottom stress, and across- and along-shelf advection of along-shelf tidal momentum (i.e., the tidal stresses).

negative, with weaker values of $-1 \times 10^{-6} \mathrm{~m} \mathrm{~s}^{-2}$ to the south and west. The along-shelf tidal stress had larger amplitude variability and shorter spatial scales than any other term. This short-scale variability in both alongshelf tidal stresses was likely the effect of known smallamplitude bathymeteric variability—referred to as sorted grain-size features (Goff et al. 2005) —on the along-shelf tidal velocities. As described by Ganju et al. (2011), these features have along-shelf spatial scales of $1-2 \mathrm{~km}$ and cause a Bernoulli-like effect between along-shelf velocity and pressure as the tidal flow passes over them.

Comparisons of the momentum terms along a line of constant latitude or longitude gives a more in-depth view of the dominant momentum terms through the center of the recirculation. Examining the terms in the along-shelf momentum balance along $41^{\circ} 19^{\prime} \mathrm{N}$ (Fig. 13, top-left panel), the along-shelf tidal stress was by far the largest of the estimated terms, having large,
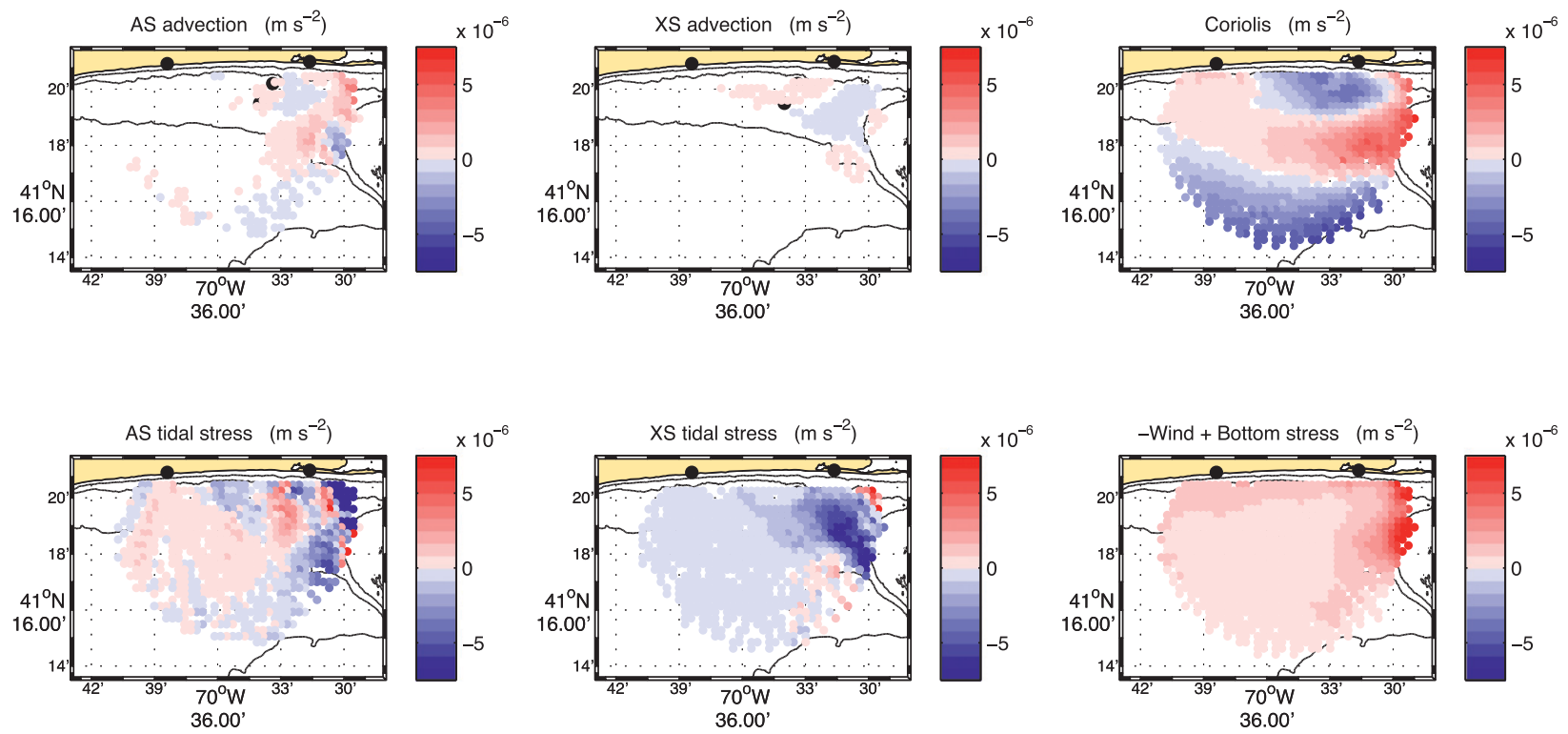

FIG. 12. As in Fig. 11, but for the across-shelf momentum balance, as in Eq. (4). 

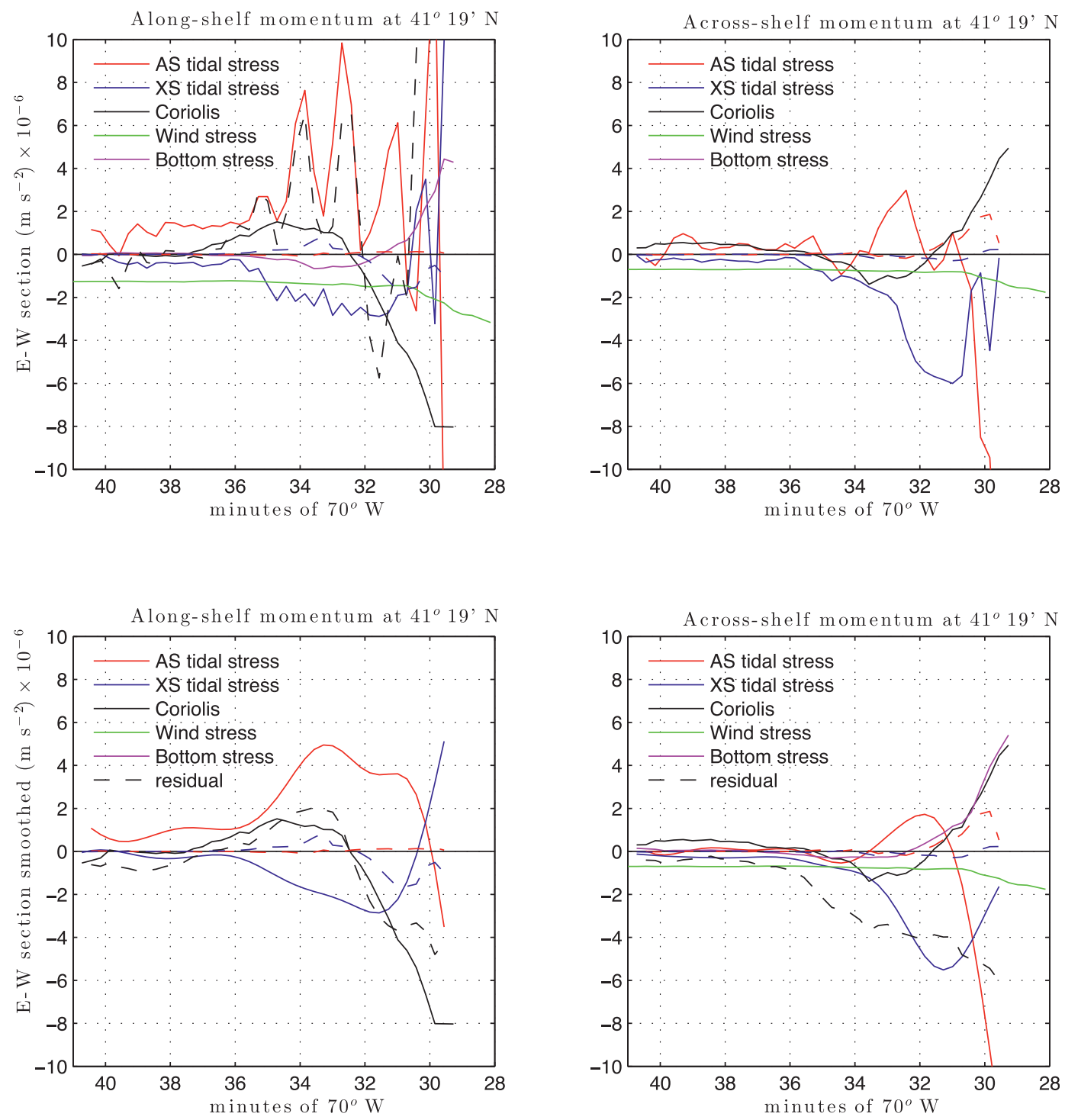

FIG. 13. Major terms in the mean along- and across-shelf momentum balance through the center of the recirculation along $41^{\circ} 19^{\prime} \mathrm{N}$ with the (top) raw and (bottom) smoothed tidal stresses. The residual momentum forcing, the sum of all terms in each panel, is shown as the black dashed line in the bottom only.

$\sim 5 \times 10^{-6} \mathrm{~m} \mathrm{~s}^{-2}$, fluctuations over short spatial scales east of $70^{\circ} 35^{\prime} \mathrm{W}$. These fluctuations were not balanced by any other estimated term but were consistent with known sorted grain-size bathymetric features (Goff et al. 2005). However, these features, having along-shelf spatial scales of $1-2 \mathrm{~km}$, cannot be fully resolved by the spatial gradients estimated from the HF radar dataset. Thus, to focus on the larger-scale momentum interactions, the tidal stress terms were spatially smoothed using a filter with a 3-km-length scale (Fig. 13, bottom panels).

At these larger scales, the along-shelf tidal stress $(\partial U U / \partial x)$ was still the dominant term in the along-shelf balance. The dominant tidal stress was partially offset by the wind stress on the western side of the domain and a combination of the across-shelf tidal stress, wind stress, and bottom stress to the east (Fig. 13). The residual momentum term-the sum of all known terms-was composed mostly of an unbalanced Coriolis term from $70^{\circ} 36^{\prime}$ to $70^{\circ} 31^{\prime} \mathrm{W}$. Bottom stress becomes more important along the eastern edge, decreasing the residual momentum. In contrast, the across-shelf momentum balance was dominated by an Ekman balance between the Coriolis term and the wind in the east, and the across-shelf tidal stress through the recirculation region. A strong positive Coriolis term and bottom stress offset much of the large along-shelf tidal stress at the eastern 

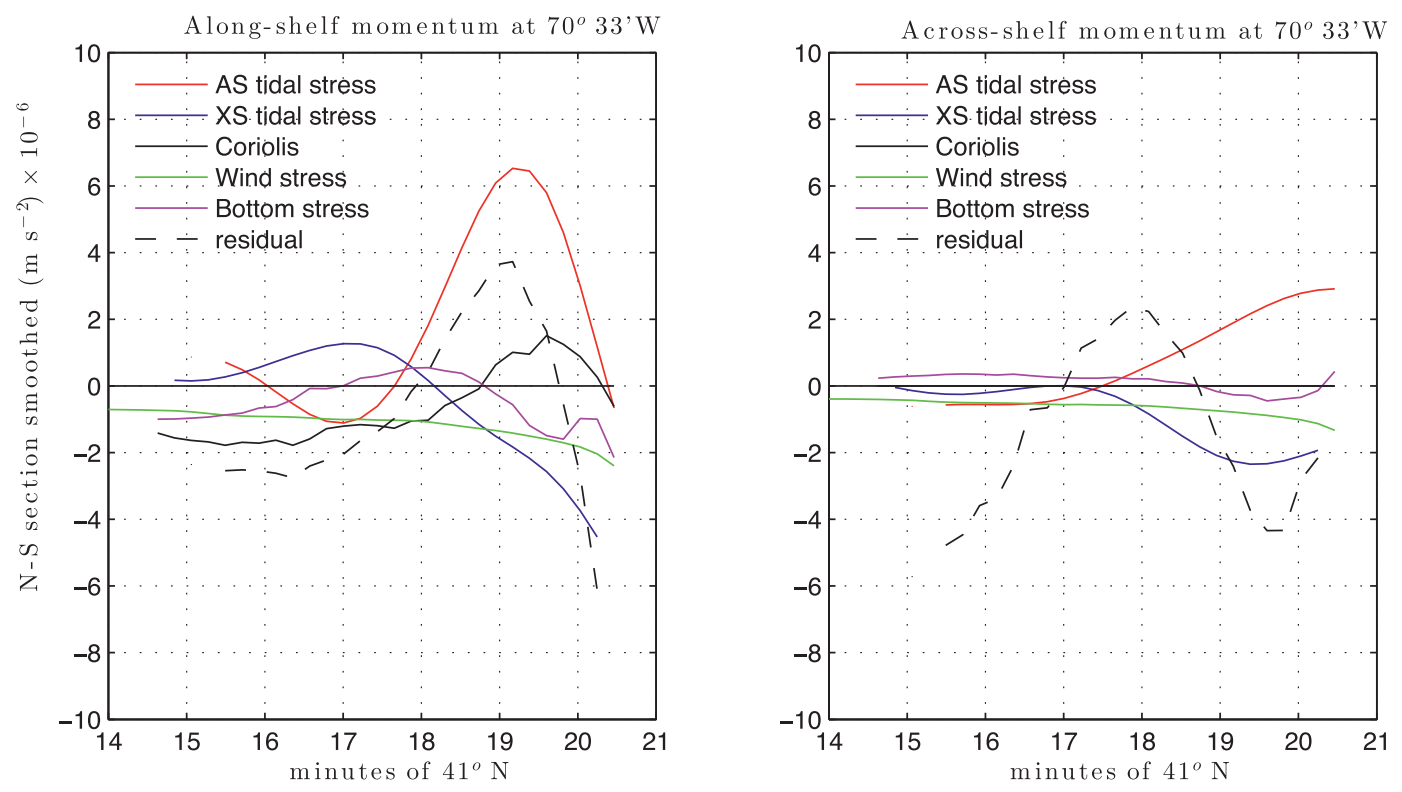

FIG. 14. Major terms in the mean along- and across-shelf shelf momentum balance through the center of the recirculation along $70^{\circ} 33^{\prime} \mathrm{W}$. Similar to the bottom panels of Fig. 13, the tidal stresses were spatially smoothed and the residual momentum term is shown as the black dashed line.

edge. The residual momentum term, the sum of all estimated terms, increased approximately linearly from zero at $70^{\circ} 38^{\prime} \mathrm{W}$ to $-6 \times 10^{-6} \mathrm{~m} \mathrm{~s}^{-2}$ at the eastern edge.

Along $70^{\circ} 33^{\prime} \mathrm{W}$, the along-shelf balance was dominated by the Coriolis term south of $41^{\circ} 17^{\prime} \mathrm{N}$ (Fig. 14). However, between $41^{\circ} 17^{\prime}$ and $41^{\circ} 20^{\prime} \mathrm{N}$, the across-shelf tidal stress (blue line) was equal and opposite to the Coriolis term. In this area the residual momentum is positive owing to the large along-shelf tidal stress. In the across-shelf momentum balance along $70^{\circ} 33^{\prime} \mathrm{W}$, the tidal stress terms offset each other, and the Coriolis term is essentially unbalanced by any of the measured terms. Thus the residual momentum term closely followed the Coriolis term.

\section{Discussion}

The mean circulation on the inner shelf south of Martha's Vineyard exhibits a spatially variable structure that can potentially drive significant across-shelf exchange. In the mean, a portion of the surface waters in the along-shelf jet located offshore turns northward with velocities near $2 \mathrm{~cm} \mathrm{~s}^{-1}$ and becomes part of the northeastward jet that forms the eastward side of the recirculation (Fig. 6). As northward velocities along $41^{\circ} 17^{\prime} \mathrm{N}$ are all positive or near zero, this northward transport does not return at the surface within the domain and must be balanced by an along-shelf flow out of the domain or offshore flow at depth outside of the jet. Thus, the observed mean circulation results in a lateral exchange that advects offshore waters onshore along the eastern boundary of the domain. This section discusses the implications of this spatially variable circulation on the exchange of heat across the inner shelf and puts the advective heat flux divergence results presented above in context with previous studies on depth-dependent heat flux divergence. Additionally, the ability of a simple model of tidally rectified flow to predict the horizontal structure of the northeastward jet as well as the acrossshelf pressure gradient inferred from the residual momentum term is investigated.

\section{a. Implications for the inner-shelf heat balance}

Examining data from an across-shelf section near $70^{\circ} 34^{\prime} \mathrm{W}$, Fewings and Lentz (2011) explained the acrossshelf cooling of the surface waters south of Martha's Vineyard using a simple two-layer model that balanced a weak upwelling circulation and surface heating with vertical mixing across the interface. During summer, Fewings and Lentz found that a heat balance between surface warming and upwelling-driven cooling acted to keep the inner shelf cooler than a 1D heat balance would predict. Although the driver of the upwelling circulation was not fully identified, the model found that a reasonable amount of vertical mixing or entrainment between the layers could also cool the waters as they moved offshore, offering an explanation for the across-shelf temperature gradient found in the moored observations.

However, given the spatial structure of the SST anomaly results presented here, the observed acrossshelf temperature gradient observed in Fewings and 
Lentz (2011) is unlikely to be due solely to a twodimensional upwelling circulation. Thus, we hypothesize that much of the upwelling-driven cooling described by Fewings and Lentz could be due to the lateral influx of cooler waters from the inshore westward jet. At the location of the node, this provides twice the potential cooling of the time-varying AHF divergence, likely a product of the mean upwelling circulation that they describe, and matches the amount of cooling Fewings and Lentz found necessary to close the heat balance over the inner shelf.

The area of warmer water observed inshore and to the west was also seen in the model simulations described by Wilkin (2006) and Hong et al. (2009). In Fig. 3 of Wilkin (2006), the advection of warmer water through the channel and to the west forms a bulge of warmer waters over the inner shelf south of Martha's Vineyard, although the modeled bulge was located farther east than SST images would suggest (cf. our Fig. 7 to Wilkin's Fig. 2). A key difference between the across-shelf analysis of Fewings and Lentz (2011) and the results of Wilkin (2006) is that the advective terms estimated by Wilkin, shown in his Figs. 10 and 11, are based on both along- and across-shelf advection of temperature, while Fewings and Lentz were only able to consider the across-shelf gradient. As shown here, with the observed recirculation and the nonnegligible along-shelf SST gradients, the along-shelf advection of temperature is likely to play a larger role in the overall heat balance than previously described.

\section{b. Inferring mean pressure gradients and sea level height}

Our examination of the momentum balances found that tidal stresses in the northeastern area of the domain can be important in driving the momentum balance in the component most closely aligned with the direction of the mean circulation (i.e., the across-shelf equation along $41^{\circ} 19^{\prime} \mathrm{N}$ and the along-shelf equation along $70^{\circ} 33^{\prime} \mathrm{W}$ ). However, in the component normal to the mean circulation-the along-shelf equation along $41^{\circ} 19^{\prime} \mathrm{N}$ and the across-shelf equation along $70^{\circ} 33^{\prime} \mathrm{W}-$ these terms tend to oppose each other outside of the extreme eastern side of the recirculation, and the dominant unbalanced term was the Coriolis term. In the "across stream" direction, much of the unbalanced momentum shown by the residual momentum term might be offset by a geostrophic balance with the unmeasured pressure gradient. In the "downstream" directions, as also illustrated by Ganju et al. (2011), an ageostrophic balance between the unbalanced tidal stress and the downstream pressure gradient serves as a primary dynamical balance.
Thus, if the residual momentum terms were due entirely to the unmeasured depth-independent pressure gradients, whether geostrophic or ageostrophic, the spatial distribution of the residual momentum term could be used to infer the magnitude of the along- and across-shelf pressure gradients. Given the uncertainties of the Coriolis and tidal stress terms described above, these inferred pressure gradients (Fig. 15) are highly speculative but, combined, allow an estimate of the relative change in mean sea level height over the study area.

The spatial structures of the inferred pressure gradients, or the negative of the residual momentum terms from Figs. 13 and 14, are shown in Fig. 15 as if they were on the rhs of Eqs. (3) and (4). The along-shelf pressure gradient has a series of ridges of alternating positive and negative pressure gradients along the eastern side. To the west, the gradients are more uniform, becoming more positive moving to the south and west. For the across-shelf residual, assumed here to be due to the across-shelf pressure gradient, large positive values exist both in- and offshore, with more negative values in the middle of the domain. These gradients were integrated outward from a centrally located point at $41^{\circ} 18^{\prime} \mathrm{N}$, $70^{\circ} 36^{\prime} \mathrm{W}$, with an assumed reference level of zero, to estimate the spatial structure of the inferred sea level height anomaly (SLHa). A low SLHa region around the center of the recirculation is immediately apparent, with higher SLHa to the south, east, and north. Mean pressure, or sea level, is lowest along the southwestern edge of the domain. The maximum range of the inferred SLHa over the domain is $\sim 0.5 \mathrm{~cm}$.

\section{c. Predictability of the tidal rectified flow}

The radar-based results described above offer more details about the spatial extent of the recirculation hinted at in Ganju et al. (2011) and describe its seasonal variability owing to winter/summer differences in the tidal stresses. Tidal rectification was found by Ganju et al. to be the main driver of the depth-averaged mean circulation as the results of their high-resolution simulations forced only by the tides matched the moored observations of Lentz et al. (2008) and Fewings (2007) reasonably well. Here we demonstrate that, despite the complex bathymetry and short along-shelf spatial scales present, the basic structure of the northeastward jetthe largest feature of the recirculation-as well as the inferred across-shelf pressure gradients across the jet, can be adequately predicted using the simple theory for tidal rectification described by Loder (1980).

To show the correspondence of the observed northeastward jet to the Loder (1980) model of tidal rectification, model predictions were calculated for across-shelf 

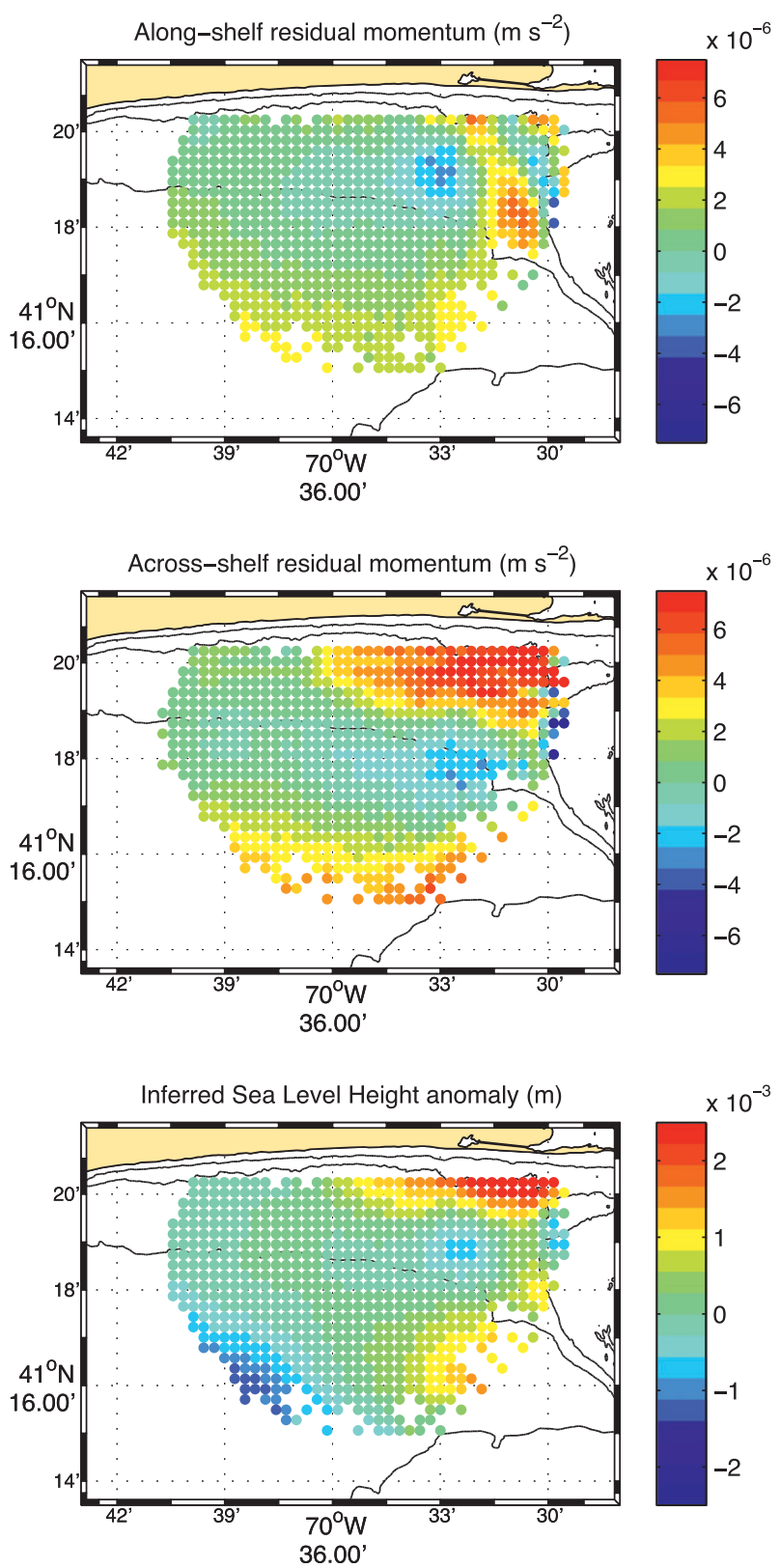

FIG. 15. (top, middle) Spatial structure of the residual momentum terms from all times, assumed due to unmeasured along- and across-shelf pressure gradients. Terms are shown as the negative of the residuals from Figs. 13 and 14 or as if it were on the rhs of Eqs. (3) and (4). (bottom) Mean SLHa found by integrating the inferred pressure gradients outward from a reference point at $41^{\circ} 18^{\prime} \mathrm{N}$, $70^{\circ} 36^{\prime} \mathrm{W}$.

lines emanating from the center of the recirculation region at bearing angles of $70^{\circ}, 90^{\circ}$, and $110^{\circ} \mathrm{T}$. Developed to describe the depth-averaged flow over Georges Bank, the Loder model uses continuity and a combination of Coriolis, advection, and bottom friction to drive a rectified flow along the shelf. Following Eqs. (31) and (28) of Loder (1980) and given an across-shelf bathymetric profile and a tidal amplitude, phase, and ratio of the semimajor and semiminor axes at its offshore edge, predictions of the fully nonlinear across-shelf structure of the depth-averaged along-shelf velocity as well as the across-shelf gradient in sea level height can be made. The lines at bearing angles $70^{\circ}, 90^{\circ}$, and $110^{\circ} \mathrm{T}$ shown in Fig. 6 were chosen as the observed mean velocities were oriented predominantly normal to the lines themselves, and along the nearby isobaths. The $M_{2}$ tidal amplitude from the center of the recirculation was used as the tidal forcing, along with a drag coefficient of $r=1.5 \times 10^{-3}$ (Kirincich et al. 2010).

Along each of the lines, the predicted "along shelf" velocity magnitude and spatial structure is quite similar to that observed (Fig. 16). Thus, despite the Loder (1980) assumption that the scale of along-shelf variations in bathymetry are much longer than the acrossshelf scale—clearly not true here-this simple model for tidal rectification appears to explain large portions of the northeastward jet, the dominant component of the recirculation. Similar comparisons between the observed along-shelf velocities on the north side of the recirculation region and model predictions do not yield such good agreement, indicating that the forcing mechanism is either a more complex tidal rectification or a downstream effect of the northeastward jet itself.

The sea level height gradients inferred from the residual terms of the tidally averaged momentum balance along the transect lines used in Fig. 16 were found to be similar to predictions of the across-line pressure gradient from the Loder (1980) model. As shown in the bottom panels of Fig. 16, both estimates are similar in the area of the steepest bottom slope, $2-3 \mathrm{~km}$ along the transect line but tend to diverge inshore of this point along the $90^{\circ}$ and $110^{\circ} \mathrm{T}$ transect lines. It should be noted that the inferred SLH gradients shown here, defined as the negative of the residual of all momentum terms, differs slightly from the residuals shown in Figs. 13 and 14 due to the spatial smoothing used in Fig. 13 to eliminate the effects of the sorted grain size features that dominate the variability of the tidal stresses outside of the northeastward jet.

\section{Summary}

Using a combination of HF radar, satellite SST, and in situ observations collected during 2011, this study has examined the spatial structure of tidal velocities over the inner shelf south of Martha's Vineyard, as well as the annual-mean surface circulation, its seasonal variability, and the processes that influence its spatial structure. Tides dominate the surface velocity signals, with constituent amplitudes up to $35 \mathrm{~cm} \mathrm{~s}^{-1}$ and variations of 

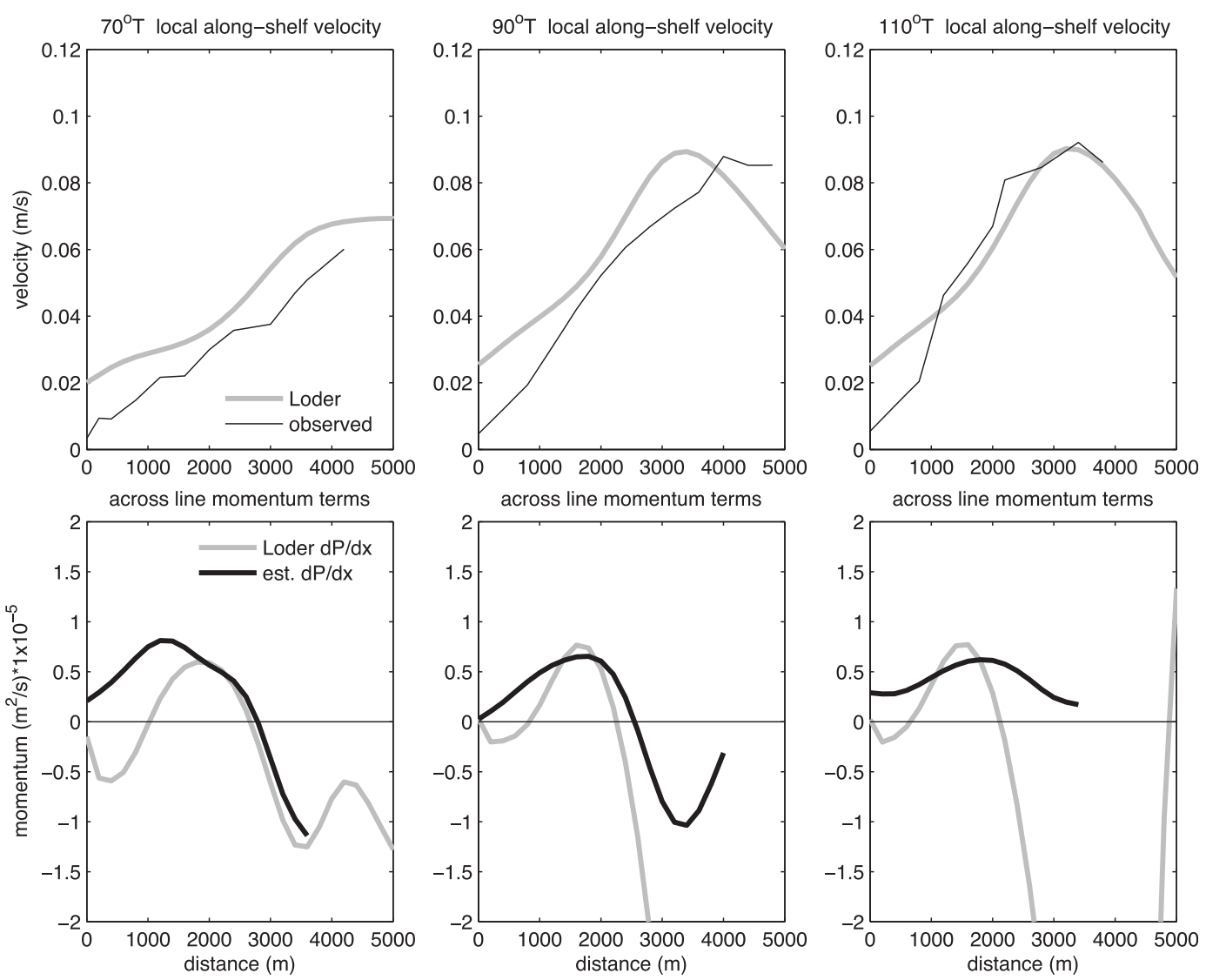

FIG. 16. (top) Comparisons of observed mean surface currents for across-shelf lines emanating from the center of the recirculation region at bearing angles of $70^{\circ}, 90^{\circ}$, and $110^{\circ} \mathrm{T}$ with predictions from the Loder (1980) tidal rectification model. (bottom) Estimated and Loder (1980) predicted across-line pressure gradients.

$25 \mathrm{~cm} \mathrm{~s}^{-1}$ and $90^{\circ}$ in phase across the $20-\mathrm{km}$ domain. Averaged over 11 months, the mean surface velocities were dominated by a recirculation in the northeast corner forced by tidal rectification and the northeastward jet, a westward jet offshore, and a region of weak circulation inshore to the west. Tidal stresses dominated the spatial variability of the along- and across-shelf mean momentum balances as the bathymetry shoaled to the east, but tended to offset each other across the recirculation region. The size and intensity of the recirculation was larger during summer. Differences in inferred pressure gradients, attributed to tidal effects and wind, accounted for much of the differences between summer and winter mean circulation conditions, including the shape and magnitude of the observed recirculation. During summer, the mean tidally rectified circulation played a dominant role in setting the pattern of mean SST anomalies as well as the mean and timedependent advective heat flux divergence. During winter, advective heat flux divergence had a more limited effect. These findings provide context for ongoing work examining the spatial variability of wind-driven surface circulation during the same time period. The strong spatial structure found in the observations confirms the structure found in previous modeling efforts, and implies that the tidally driven background circulation has the potential to interact with wind-driven event forcings to lead to spatially variable across-shelf exchanges.

Acknowledgments. The development and operation of the WHOI HF radar system has been supported by the Woods Hole Oceanographic Institution. The ancillary data used in this work was collected by Janet Fredricks and the Martha's Vineyard Coastal Observatory team who, for over a decade, have been deploying and maintaining the core instruments and infrastructure of the MVCO. We also acknowledge Craig Marquette for his efforts in deploying and maintaining the SWWIM array of moorings.

\section{REFERENCES}

Barth, J., S. Pierce, and R. Castelao, 2005: Time-dependent, winddriven flow over a shallow midshelf submarine bank. J. Geophys. Res., 110, C10S05, doi:10.1029/2004JC002761. 
Castelao, R., and J. Barth, 2006: The relative importance of wind strength and along-shelf bathymetric variations on the separation of a coastal upwelling jet. J. Phys. Oceanogr., 36, 412-425.

Chant, R., S. Glenn, and J. Kohut, 2004: Flow reversals during upwelling conditions on the New Jersey inner shelf. J. Geophys. Res., 109, C12S03, doi:10.1029/2003JC001941.

Fewings, M., 2007: Cross-shelf circulation and momentum and heat balances over the inner continental shelf near Martha's Vineyard, Massachusetts. Ph.D. thesis, MIT-WHOI Joint Program, 267 pp.

— tinental shelf at Martha's Vineyard Coastal Observatory. J. Geophys. Res., 115, C12023, doi:10.1029/2009JC005578.

—, and - 2011: Summertime cooling of the shallow continental shelf. J. Geophys. Res., 116, C07015, doi:10.1029/2010JC006744.

,-- , and J. Fredericks, 2008: Observations of cross-shelf flow driven by cross-shelf winds on the inner continental shelf. J. Phys. Oceanogr., 38, 2358-2378.

Ganju, N., S. Lentz, A. Kirincich, and J. Farrar, 2011: Complex mean circulation over the inner-shelf south of Martha's Vineyard revealed by observations and a high-resolution model. J. Geophys. Res., 116, C10036, doi:10.1029/2011JC007035.

Geyer, W., 1993: Three-dimensional tidal flow around headlands. J. Geophys. Res., 98 (C1), 955-966.

Goff, J., and Coauthors, 2005: Detailed investigation of sorted bedforms or rippled scour depressions within the Martha's Vineyard Coastal Observatory, Massachusetts. Cont. Shelf Res., 25, 461-484.

He, R., and J. Wilkin, 2006: Barotropic tides on the southeast New England shelf: A view from a hybrid data assimilative modeling approach. J. Geophys. Res., 111, C08002, doi:10.1029/ 2005 JC003254.

Hong, X., P. Martin, S. Wang, and C. Rowley, 2009: High SST variability south of Martha's Vineyard: Observation and modeling study. J. Mar. Syst., 78, 59-76.

Horwitz, R., 2012: The effect of stratification on wind-driven, crossshelf circulation and transport on the inner continental shelf. Ph.D. thesis, MIT-WHOI Joint Program, 215 pp.

Kirincich, A., and J. Barth, 2009: Time-varying across-shelf Ekman transport and vertical eddy viscosity on the inner shelf. J. Phys. Oceanogr., 39, 602-620.

— S. Lentz, and G. Gerbi, 2010: Calculating Reynolds stresses from ADCP measurements in the presence of surface gravity waves using the cospectra fit method. J. Atmos. Oceanic Technol., 27, 889-907.

_ mates of surface currents using signal quality metrics: With application to the MVCO high-resolution radar system. J. Atmos. Oceanic Technol., 29, 1377-1390.

Kohut, J., S. Glenn, and R. Chant, 2004: Seasonal current variability on the New Jersey inner shelf. J. Geophys. Res., 109, C07S07, doi:10.1029/2003JC001963.
— H. Roarty, and S. Glenn, 2006: Characterizing observed environmental variability with HF Doppler radar surface current mappers and acoustic Doppler current profilers: Environmental variability in the coastal ocean. IEEE J. Oceanic Eng., 31, 876-884, doi:10.1109/JOE.2006.886095.

Kosro, P., 2005: On the spatial structure of coastal circulation off Newport, Oregon, during spring and summer 2001 in a region of varying shelf width. J. Geophys. Res., 110, C10S06, doi:10.1029/2004JC002769.

Large, W., and S. Pond, 1981: Open ocean momentum flux measurements in moderate to strong winds. J. Phys. Oceanogr., 11, 324-336.

Lentz, S., 2008: Observations and a model of the mean circulation over the Middle Atlantic Bight continental shelf. J. Phys. Oceanogr., 38, 1203-1221.

_- M. Fewings, P. Howd, J. Fredericks, and K. Hathaway, 2008: Observations and a model of undertow over the inner continental shelf. J. Phys. Oceanogr., 38, 2341-2357.

Loder, J., 1980: Topographic rectification of tidal currents on the sides of Georges Bank. J. Phys. Oceanogr., 10, 1399-1416.

Paduan, J., and H. Graber, 1997: Introduction to high-frequency radar: Reality and myth. Oceanography, 10, 36-39.

Pawlowicz, R., B. Beardsley, and S. Lentz, 2002: Classical tidal harmonic analysis including error estimates in MATLAB using T_TIDE. Comput. Geosci., 28, 929-937.

Shearman, R., and S. Lentz, 2004: Observations of tidal variability on the New England shelf. J. Geophys. Res., 109, C06010, doi:10.1029/2003JC001972.

Song, Y., D. Haidvogel, and S. Glenn, 2001: Effects of topographic variability on the formation of upwelling centers off New Jersey: A theoretical model. J. Geophys. Res., 106 (C5), 9223 9240.

Stewart, R., and J. Joy, 1974: HF radio measurements of surface currents. Deep-Sea Res., 21, 1039-1049.

Tilburg, C., and R. Garvine, 2003: Three-dimensional flow in a shallow coastal upwelling zone: Alongshore convergence and divergence on the New Jersey shelf. J. Phys. Oceanogr., 33, 2113-2125.

Ullman, D., J. O'Donnell, J. Kohut, T. Fake, and A. Allen, 2006: Trajectory prediction using HF radar surface currents: Monte Carlo simulations of prediction uncertainties. J. Geophys. Res., 111, C12005, doi:10.1029/2006JC003715.

Wilkin, J., 2006: The summertime heat budget and circulation of southeast New England shelf waters. J. Phys. Oceanogr., 36, 1997-2011.

Yankovsky, A., and D. Chapman, 1995: Generation of mesoscale flows over the shelf and slope by shelf wave scattering in the presence of a stable, sheared mean current. J. Geophys. Res., 100 (C4), 6725-6742.

, and R. Garvine, 1998: Subinertial dynamics on the inner New Jersey shelf during the upwelling season. J. Phys. Oceanogr., 28, 2444-2458. 